\title{
Optimising drone flight planning for measuring horticultural tree crop structure
}

\author{
Yu-Hsuan Tu ${ }^{\mathrm{a}, \mathrm{b}, \mathrm{c}, *}$, Stuart Phinn ${ }^{\mathrm{a}, \mathrm{b}}$, Kasper Johansen ${ }^{\mathrm{a}, \mathrm{c}}$, Andrew Robson ${ }^{\mathrm{b}, \mathrm{d}}$, Dan Wu ${ }^{\mathrm{a}, \mathrm{b}}$ \\ a Remote Sensing Research Centre, School of Earth and Environmental Sciences, The University of Queensland, St Lucia 4072, QLD, Australia \\ ${ }^{\mathrm{b}}$ Joint Remote Sensing Research Program, School of Earth and Environmental Sciences, The University of Queensland, St Lucia 4072, QLD, Australia \\ ${ }^{\mathrm{c}}$ Hydrology, Agriculture and Land Observation Group, Water Desalination and Reuse Center, King Abdullah University of Science and Technology, Thuwal 23955-6900, Saudi Arabia \\ ${ }^{\mathrm{d}}$ Precision Agriculture Research Group, School of Science and Technology, University of New England, Armidale 2351, NSW, Australia
}

\section{A R T I C LE IN F O}

\section{Keywords}

Drone

UAS

UAV

Flight planning

Horticulture

Tree structure measurement

\begin{abstract}
A B S T R A C T
In recent times, multi-spectral drone imagery has proved to be a useful tool for measuring tree crop canopy structure. In this context, establishing the most appropriate flight planning variable settings is an essential consideration due to their controls on the quality of the imagery and derived maps of tree and crop biophysical properties. During flight planning, variables including flight altitude, image overlap, flying direction, flying speed and solar elevation, require careful consideration in order to produce the most suitable drone imagery. Previous studies have assessed the influence of individual variables on image quality, but the interaction of multiple variables has yet to be examined. This study assesses the influence of several flight variables on measures of data quality in each processing step, i.e. photo alignment, point cloud densification, 3D model building, and ortho-mosaicking. The analysis produced a drone flight planning and image processing workflow that delivers accurate measurements of tree crops, including the tie point quality, densified point cloud density, and the measurement accuracy of height and plant projective cover derived from individual trees within a commercial avocado orchard. Results showed that flying along the hedgerow, at high solar elevation and with low image pitch angles improved the data quality. Optimal flying speed needs to be set to achieve the required forward overlap. The impacts of each image acquisition variable are discussed in detail and protocols for flight planning optimisation for three scenarios with different drone settings are suggested. Establishing protocols that deliver optimal image acquisitions for the collection of drone data over horticultural tree crops, will create greater confidence in the accuracy of subsequent algorithms and resultant maps of biophysical properties.
\end{abstract}

\section{Introduction}

Tree crops contribute a large proportion of the global agricultural economy (Barlow, 1997) and are considered to be essential contributors to the future food and nutritional security of a growing global population (Davies and Bowman, 2016). In Australia, a report by Econtech and Institute (2005) identified that fruit production and growing activities contributed $16 \%$ of the total agriculture-dependent GDP. Hence, suitable information for site-specific crop management of orchards and their individual trees is important to minimise production costs and maximise productivity and quality (Ushaa and Singh, 2013). The information required for this type of management includes regularly updated assessments of crop or tree structure (height, canopy properties, number of fruit) and condition. Remote sensing is an effec- tive tool for mapping tree structural variables, including condition, vigour, photosynthetic capacity, and yield potential (Rahman et al., 2018; Robson et al., 2017; Tu et al., 2019; Viau et al., 2005). Tree crop structural attributes, such as tree height, canopy extent, and plant projective cover (PPC) have a strong correlation with condition and productivity (Salgadoe et al., 2018; Sarron et al., 2018; Schaffer et al., 2013). For instance, a fully-grown and well-established canopy architecture of avocado trees can almost guarantee maximum light interception, and thus increases annual vegetative shoot flushes to contribute the floral intensity and therefore the yield in the following spring in every alternative bearing cycle (Salazar-García et al., 2013; Schaffer et al., 2013). While information on these variables may be derived from either satellite or aircraft based remote sens-

Abbreviations: UAS, unmanned aircraft system; UAV, unmanned aerial vehicle; PPC, plant projective cover; GSD, ground sample distance; BRDF, bidirectional reflectance dis-

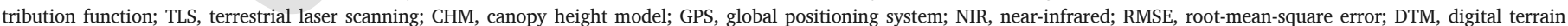

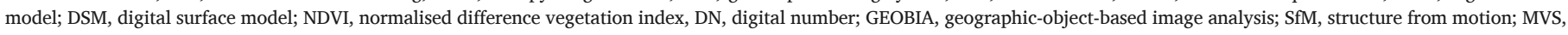
multi-view stereoscopic; PLS, partial least square; ANOVA, analysis of variance.

* Corresponding author at: Remote Sensing Research Centre, School of Earth and Environmental Sciences, The University of Queensland, St Lucia 4072, QLD, Australia.

E-mail addresses: yuhsuan.tu@uqconnect.edu.au (Y-H Tu); s.phinn@uq.edu.au (S. Phinn); kasper.johansen@kaust.edu.sa (K. Johansen); andrew.robson@une.edu.au (A. Robson); d. wu@uqconnect.edu.au (D. Wu) 
ing, data acquisitions are constrained by the time, weather, and sensor resolution.

In the past decade, imagery collected from drones has become increasingly popular for the acquisition of information to assist orchard management. With their ability to cover orchard scales $\left(<10 \mathrm{~km}^{2}\right)$, information can be acquired on-demand with very-high spatial resolution able to be obtained from miniaturized sensors designed for drones (Deng et al., 2018; Johansen et al., 2018; Tu et al., 2019; Zarco-Tejada et al., 2014). However, determining the appropriate setting for flight planning is essential, as different combinations of flight variables influence the quality and useability of final products (Aasen et al., 2018; Dandois et al., 2015; Roth et al., 2018).

Many studies have discovered that different flight planning settings, such as image overlap and flying altitude, influence estimations of tree structure variables (Dandois et al., 2015; Singh and Frazier, 2018; Torres-Sánchez et al., 2015; Zarco-Tejada et al., 2014) as well as the radiometric quality (Singh and Frazier, 2018; Tu et al., 2018). Yet investigations of these influences have been limited to only individual variables. For example, it is known that changing flying altitude changes the pixel GSD, but also produces parallax variation that influences how the features in scenes are measured and observed using computer vision techniques (Frey et al., 2018; Johansen et al., 2018; Remondino et al., 2014; Seifert et al., 2019; Tu et al., 2018). For some cameras, where the trigger speed is constrained by the input/output (I/O) speed, changing altitude will influence the forward overlap at the same time (Seifert et al., 2019; Torres-Sánchez et al., 2015). Although changing altitude is an effective approach to change the pixel GSD, this can also be achieved e.g. theoretically by changing the focal length of a sensor, or simply by placing a higher-resolution camera. This example demonstrates the complex effect that a simple change of one variable may have on drone image collection. This may be the reason that some studies have found that flight altitude had a significant impact on the accuracy of canopy structure measurements, while other studies did not (Dandois et al., 2015; Johansen et al., 2018; Torres-Sánchez et al., 2018; Zarco-Tejada et al., 2014). Therefore, it is necessary to systematically assess the effects of different drone flight variables on the quality of the derived imagery and map products.

Apart from altitude, the effect of sun angle variations has seldom been discussed in the literature on drone image data, although it has been dealt with extensively for satellite image data (Tu et al., 2018). Structural attributes such as PPC, which is the projected fraction of plant's biomass in the relation of sky, is often calculated using spectral information (Johansen et al., 2008, 2018; Salgadoe et al., 2018; Tu et al., 2019). The variation of sun angles, including solar elevation and solar azimuth causes variations in reflectance measurements of the same target due to the bidirectional reflectance distribution function (BRDF) effects (Aasen et al., 2018; Honkavaara and Khoramshahi, 2018; Singh and Frazier, 2018; Tu et al., 2018). Such observed spectral differences may cause inconsistency in the estimation of PPC. In addition, varying sun angles can influence shading within the tree canopy, which may affect the accuracy of biomass estimation (Adeline et al., 2013; Asner and Warner, 2003). Flight line pattern is another variable, which varies significantly between different studies reported in the literature, but its influence on data quality is rarely discussed.

Unlike natural forested environments, horticultural tree crops are usually planted in rows that in some cases are manually shaped to produce a continuous canopy. The influence of linear tree planting and flight direction, i.e. either flying along tree rows, across tree rows or in a grid pattern (Díaz-Varela et al., 2015; Tu et al., 2019; Zarco-Tejada et al., 2014) on the quality of image products has also received little investigation. Tu et al. (2018) indicated that the different flying directions caused inconsistency in the radiometric quality of drone im- agery due to the different solar-surface-viewing geometries. However, the impact on image 3D reconstruction of this is still undocumented. Flying speed is yet another variable, which varies significantly between different studies reported in the literatures, ranging from $3 \mathrm{~m} / \mathrm{s}$ to $17 \mathrm{~m}$ / s (Jiménez-Brenes et al., 2017; Zarco-Tejada et al., 2014). The effect of flying speed varies, depending on the type of camera shutter, the acquisition mode, and the type of drone platform, i.e. multirotor or fixed wing (Eisenbeiß, 2009; Pádua et al., 2017; Seifert et al., 2019). High flying speed tends to capture 'blurry' imagery, as it is a function of motion blur (Roth et al., 2018), especially for rolling shutter cameras (Candiago et al., 2015). Flying speed affects the forward overlap as well if the time interval of the camera trigger is fixed (Dandois et al., 2015). Additionally, flying at higher speed can increase the pitch angle of multirotor platforms, and this pitch variation also influences the viewing angle of the camera if the camera is mounted without a self-levelling gimbal. The points above, and lack of drone data acquisition protocols, make it difficult to optimise drone flight planning and imaging workflows to establish set standards of deliverables of multi-spectral drone image products (Aasen et al., 2018; Roth et al., 2018).

This study assessed several acquisition variables, including flying altitude, image side-lap, flying speed, flying directions, and solar elevation, to determine their influences on data quality and consistency, when measuring structural variables of avocado tree crops with multi-spectral drone imagery. Based on the analysis of results, optimal data acquisition protocols for flight planning of drone image collection of horticultural tree crops are presented.

\section{Material and methods}

\subsection{Study site}

The study site for this research was located in southeast Queensland, Australia, near the township of Bundaberg (coordinate: $25.144925^{\circ} \mathrm{S}$, $152.363006^{\circ} \mathrm{E}$ ). This region is one of the largest producers of Hass avocadoes in Australia (Whiley, 2000). This subtropical region has hot and humid summers, with the mean temperature at $30{ }^{\circ} \mathrm{C}$ and mean monthly rainfall at $158.9 \mathrm{~mm}$, while the temperature in winter is mild and dry, with a mean temperature at $22.8^{\circ} \mathrm{C}$ and mean monthly rainfall of $45.6 \mathrm{~mm}$ (Bureau of Meteorology, 2019). Avocado trees within this region flower during September and establish final fruit set in January. Harvesting occurs in May followed by limb pruning to maintain access to all trees and maximise light interception of tree canopies. Drone data acquisition occurred over a 1 ha area of avocado trees within a commercial orchard. The trees were planted at $5 \mathrm{~m}$ spacing along hedgerows in 2005 in an east-west orientation. Each hedgerow was $10 \mathrm{~m}$ apart, making the plant density 200 trees/ha. The data were collected in early February 2017, when the foliage density was high due to the summer leaf flush (Newett et al., 2001). The terrain was relatively flat with an average slope of 4 degrees slanting downward towards east and the average elevation of the 1 ha patch was about $60 \mathrm{~m}$ above sea level.

\subsection{Field measurements}

Terrestrial laser scanning (TLS) data and canopy photos were collected on 5 February 2017 for estimating tree height and PPC, respectively. The TLS data were acquired using a RIEGL VZ-400 laser scanner (RIEGL, Horn, Austria) mounted on a tripod at a height of about $1.5 \mathrm{~m}$. The scanner emits laser beams at a wavelength of $1550 \mathrm{~nm}$. The scanning beam divergence was $0.35 \mathrm{mrad}$. The laser can reach up to a distance of $350 \mathrm{~m}$ at $90 \%$ reflectance of targeted objects and $160 \mathrm{~m}$ at $20 \%$ target reflectance. The scanning was conducted at eight locations that surrounded the centre tree in the 1 ha study area with a scanning resolution of 0.06 degree. Due to the scanning zenith angle limit (30 
-130 degree), at each scan location, the scanning was conducted vertically, and tilted at 90 degree (horizontally) to ensure the top canopy was covered at each scan location. The total of eight scans of TLS data were registered and georeferenced in RiSCAN Pro (RIEGL, Horn, Austria). The point cloud was classified into ground and non-ground points using LAStools TM software (Rapidlasso GmbH, Gilching, Germany) and a canopy height model (CHM) at 99th percentile of 52 trees was produced based on the classified point cloud (Wu et al., 2019). The average measured tree height from the produced CHM was $8.67 \mathrm{~m}$.

Canopy photos were captured with a Nikon Coolpix AW120 digital camera (Nikon Corporation, Tokyo, Japan) for 45 trees that were evenly distributed within the 1 ha area. Eight representative photos for each tree were taken halfway between the trunk and the canopy edge during dusk. These photos were analysed in the Can-Eye software (French National Institute of Agronomical Research, Paris, France) to calculate the gap fraction and PPC for each tree. PPC is defined as the vertically projected fraction of leaves and branches in relation to sky and is calculated as one minus the proportion of the sky.

Ten AeroPoints ${ }^{\circledR}$ (Propeller Aerobotics Pty Ltd, Surry Hills, Australia) were deployed evenly in the study area to record global positioning system (GPS) information over a 5-hour period. The AeroPoint ${ }^{\circledR}$ data were subsequently post-processed with the Propeller ${ }^{\circledR}$ network correction using the GPS data from the nearest base station located $26 \mathrm{~km}$ from the study site. The calculated AeroPoint ${ }^{\circledR}$ locations were then used to geo-reference the drone imagery.

Eight greyscale gradient panels, with reflectance values ranging from $4 \%$ to $92 \%$, were also deployed next to each other for imagery radiometric correction. The panels were manufactured based on the suggestion by Wang and Myint (2015) and the reflectance values were measured with an ASD FieldSpec ${ }^{\circledR} 3$ spectrometer (Malvern Panalytical Ltd, Malvern, UK). The spectrometer reflectance measurements of each panel were resampled using ENVI (Harris Corporate, Melbourne, USA) to match them to the central wavelength and bandwidth of the four Parrot Sequoia ${ }^{\circledR}$ spectral bands.

\subsection{Drone image acquisition}

The Parrot Sequoia ${ }^{\circledR}$ multi-spectral camera ((Parrot Drone SAS, Paris, France) was used to capture the imagery for our experiment, coupled with the 3DR solo (3D Robotics, Berkeley, USA) quadcopter as the mounting platform. The system is a multi-camera design using global shutter that captures the light of the green $(550 \mathrm{~nm}, 40 \mathrm{~nm}$ bandwidth), red (660 nm, $40 \mathrm{~nm}$ bandwidth), red edge $(735 \mathrm{~nm}, 10 \mathrm{~nm}$ bandwidth), and NIR (790 nm, $40 \mathrm{~nm}$ bandwidth) part of the spectrum and records the signal in $4.8 \times 3.6 \mathrm{~mm}(1280 \times 960$ pixels $)$ separate imaging CMOS sensors. The focal length of the camera is $3.98 \mathrm{~mm}$. The camera was mounted to face downward without a self-levelling gimbal. The imaging mode was set to a fixed $1 \mathrm{~s}$ trigger speed, coinciding with the file writing speed limit to on-board internal memory. Twenty-seven flights were conducted during 2-6 Feb 2017 to provide various combinations of flight altitude, side-lap, speed, pattern, and time of day (Table 1). All the flights were conducted under clear sky condition. The images were acquired in a continuous flying mode. Some of the flights only covered 0.25 ha in the centre of 1 ha study area due to the flight duration limit of the drone. It is noted that configuration number 13 is missing as it was unsuccessful due to incorrect settings so that the flight numbers were all offset by 1 after configuration number 13 in order to be faithful to our dataset numbering. The configuration numbers $26-28$ were conducted under specific solar elevation angles $\left(<40^{\circ}\right.$, $<30^{\circ}$, and $<20^{\circ}$, respectively). Besides, the inaccurate on-board GPS prevented accurate control of forward overlap, so it did not be included as a variable.
Table 1

Different settings of the 27 drone campaigns. It is noted that configuration number 13 is missing as it was unsuccessful due to wrong setting. The pattern along means the drone flight line direction occurred in the direction along the hedgerows, while the grid pattern included both along and across hedgerows. The configuration numbers with * means they were conducted in the central 0.25 ha area.

\begin{tabular}{|c|c|c|c|c|c|}
\hline $\begin{array}{l}\text { Config } \\
\text { no. }\end{array}$ & $\begin{array}{l}\text { Flight } \\
\text { altitude } \\
\text { (m) }\end{array}$ & $\begin{array}{l}\text { Side- } \\
\text { lap (\%) }\end{array}$ & $\begin{array}{l}\text { Speed } \\
(\mathrm{m} / \mathrm{s})\end{array}$ & $\begin{array}{l}\text { Flight } \\
\text { pattern }\end{array}$ & Date/Time \\
\hline 1 & 100 & 90 & 5 & Along & $\begin{array}{l}3 \text { Feb 2017/ } \\
1: 24-1: 36 \mathrm{PM}\end{array}$ \\
\hline 2 & 100 & 80 & 5 & Grid & $\begin{array}{l}3 \text { Feb 2017/ } \\
\text { 12:46-12:59 PM }\end{array}$ \\
\hline 3 & 100 & 70 & 5 & Along & $\begin{array}{l}3 \text { Feb } 2017 / \\
2: 42-2: 47 \text { PM }\end{array}$ \\
\hline 4 & 100 & 60 & 5 & Along & $\begin{array}{l}6 \text { Feb 2017/11:54 } \\
\text { AM-12:00 PM }\end{array}$ \\
\hline 5 & 75 & 90 & 5 & Along & $\begin{array}{l}2 \text { Feb 2017/ } \\
\text { 1:51-2:05 PM }\end{array}$ \\
\hline 6 & 75 & 80 & 5 & Grid & $\begin{array}{l}2 \text { Feb 2017/ } \\
2: 11-2: 25 \mathrm{PM}\end{array}$ \\
\hline 7 & 75 & 70 & 5 & Along & $\begin{array}{l}5 \text { Feb 2017/11:58 } \\
\text { AM-12:04 PM }\end{array}$ \\
\hline 8 & 75 & 60 & 5 & Along & $\begin{array}{l}5 \text { Feb 2017/ } \\
11: 20-11: 24 \text { AM }\end{array}$ \\
\hline$* 9$ & 50 & 90 & 5 & Along & $\begin{array}{l}5 \text { Feb 2017/ } \\
11: 47-11: 53 \mathrm{AM}\end{array}$ \\
\hline *10 & 50 & 80 & 5 & Grid & $\begin{array}{l}5 \text { Feb 2017/ } \\
12: 34-12: 40 \text { PM }\end{array}$ \\
\hline 11 & 50 & 70 & 5 & Along & $\begin{array}{l}5 \text { Feb 2017/ } \\
\text { 12:14-12:21 PM }\end{array}$ \\
\hline 12 & 50 & 60 & 5 & Along & $\begin{array}{l}5 \text { Feb 2017/ } \\
2: 16-2: 23 \text { PM }\end{array}$ \\
\hline *14 & 25 & 80 & 5 & Along & $\begin{array}{l}5 \text { Feb 2017/ } \\
\text { 2:05-2:11 PM }\end{array}$ \\
\hline 15 & 25 & 70 & 5 & Along & $\begin{array}{l}2 \text { Feb 2017/ } \\
2: 39-2: 52 \mathrm{PM}\end{array}$ \\
\hline 16 & 25 & 60 & 5 & Along & $\begin{array}{l}3 \text { Feb 2017/ } \\
2: 07-2: 18 \text { PM }\end{array}$ \\
\hline *17 & 25 & 80 & 3 & Along & $\begin{array}{l}3 \text { Feb 2017/ } \\
2: 29-2: 38 \text { PM }\end{array}$ \\
\hline *18 & 25 & 80 & 8 & Along & $\begin{array}{l}5 \text { Feb 2017/ } \\
1: 26-1: 30 \mathrm{PM}\end{array}$ \\
\hline *19 & 25 & 80 & 10 & Along & $\begin{array}{l}6 \text { Feb 2017/ } \\
\text { 11:10-11:14 AM }\end{array}$ \\
\hline *20 & 50 & 80 & 3 & Along & $\begin{array}{l}5 \text { Feb 2017/ } \\
12: 45-12: 50 \mathrm{PM}\end{array}$ \\
\hline$* 21$ & 50 & 80 & 8 & Along & $\begin{array}{l}6 \text { Feb 2017/ } \\
\text { 11:18-11:22 AM }\end{array}$ \\
\hline *22 & 50 & 80 & 10 & Along & $\begin{array}{l}6 \text { Feb 2017/ } \\
\text { 11:39-11:42 AM }\end{array}$ \\
\hline 23 & 75 & 80 & 3 & Along & $\begin{array}{l}3 \text { Feb 2017/ } \\
\text { 1:06-1:17 PM }\end{array}$ \\
\hline 24 & 75 & 80 & 8 & Along & $\begin{array}{l}5 \text { Feb 2017/ } \\
1: 51-1: 57 \mathrm{PM}\end{array}$ \\
\hline 25 & 75 & 80 & 10 & Along & $\begin{array}{l}6 \text { Feb 2017/ } \\
11: 31-11: 37 \text { AM }\end{array}$ \\
\hline 26 & 75 & 80 & 5 & Grid & $\begin{array}{l}5 \text { Feb 2017/ } \\
3: 31-3: 45 \text { PM }\end{array}$ \\
\hline 27 & 75 & 80 & 5 & Grid & $\begin{array}{l}5 \text { Feb 2017/ } \\
4: 14-4: 27 \mathrm{PM}\end{array}$ \\
\hline 28 & 75 & 80 & 5 & Grid & $\begin{array}{l}2 \text { Feb 2017/ } \\
5: 34-5: 48 \text { PM }\end{array}$ \\
\hline
\end{tabular}

\subsection{Image pre-processing: geometric}

Agisoft MetaShape Pro (previously called Agisoft PhotoScan Pro, Agisoft LLC, St. Petersburg, Russia) was used for pre-processing of the drone image data. The photos from each flight were reviewed to omit redundant and blurred photos before importing the photos into Agisoft MetaShape Pro. The photos of those flights, where image data were col- 
lected in a grid-pattern, were further divided into three datasets: along-row flight, cross-row flight, and the compilation of both. Therefore, the total number of datasets increased to 39 rather than the original 27 datasets. The photos for each dataset were aligned automatically first, with the limits of key point and tie point being set to 40,000 and 10,000, respectively. The ground control points (GCPs) derived from AeroPoint ${ }^{\circledR}$ measurements were manually marked for the individual datasets. All the datasets had a geo-referenced root-mean-square error (RMSE) of less than one pixel based on the GCPs, except configuration number 19 (RMSE $=0.59 \mathrm{~m}$ ) due to the poor photo alignment results caused by insufficient image forward overlap. The rest of the processing steps, including photogrammetry point cloud densification, ground point classification, elevation model generation, and orthomosaicking, were executed automatically in MetaShape Pro with the aid of an in-house Python script. The noise filter in the point cloud densification was set to mild to remove points which have high reprojection errors, and preserve as many details of the tree crowns as possible. The densified point cloud was classified into two classes: ground and others. Three key parameters needed to be determined: (1) maximum angle, which set the limitation for an angle between the terrain and the points of interest; (2) maximum distance, which set the limitation for the distance between the terrain and the points of interest; and (3) cell size, which was set to approximately the width of the largest object in the scene with no ground points (Agisoft LLC, 2019). In our case, the maximum angle was set to 13 degrees, and the cell size was set to $10 \mathrm{~m}$. The maximum distance varied between datasets, which was set to twice the GSD. The ground points were used to generate a digital terrain model (DTM), while all points were used to produce a digital surface model (DSM). Colour correction was enabled to correct the vignetting effects and reduce brightness variation caused by dynamic photographic parameter (e.g. ISO value, shutter speed, etc.) settings of the Parrot Sequoia ${ }^{\circledR}$ camera (refer to Tu et al. (2019) for more details). The processing report, densified point cloud, DSM, DTM, and orthomosaic of each dataset were exported for quality assessment and generating analysis-ready data.

\subsection{Image pre-processing: radiometric}

NIR band or normalised difference vegetation index (NDVI) are needed to estimate PPC of individual tree crowns (Tu et al., 2019). Therefore, it was imperative to convert the orthomosaics of the red and NIR bands to at-surface reflectance to produce NDVI images. A simplified empirical correction was applied using the digital number (DN) of the greyscale field calibration panels captured during image acquisition and the method of linear regression to convert the pixel values of the red and NIR bands into at-surface reflectance for all of the datasets. This was done for all images, except acquisition configuration numbers 18 and 19 (Table 1), where the full area of panels was not successfully retrieved from the images; and configuration number 28, where the panels were shaded due to the low solar elevation. Therefore, the NDVI images from these three datasets were not produced. However, the NIR bands from the three datasets were still used to produce measurements of PPC. The initial at-surface reflectance images contained negative values in the tree crown areas due to shaded leaves. Similar to dark pixel subtraction (Jensen, 2016), the minimum pixel values within the tree crown areas were calculated and the offsets of minimum values were applied to respective at-surface reflectance images to make sure the minimum at-surface reflectance within tree crowns was zero. The subsequent at-surface reflectance images of the red and NIR bands were applied to produce NDVI images for each dataset.

\subsection{Extraction of information for individual trees}

The image-derived canopy height models (CHM), NIR band, and NDVI were then imported into the eCognition Developer software (Trimble, Munich, Germany) to delineate individual trees. The CHMs of individual datasets were derived by subtracting the DTM from the DSM produced from the same dataset. A semi-automatic delineation method was applied to the pre-processed and orthomosaiced image data for configuration number 6 (Table 1) to delineate the extent of tree crowns for the 53 trees with tree height measurements from derived from the TLS data, and the 45 trees with field derived PPC measurements. The datasets only covering the central 0.25 ha area included 35 of the 53 trees with TLS scans and 17 of the 45 trees with field measured PPC. As all the datasets were geo-referenced, the tree crown delineation extents aligned very well for all data sets. The only exception was configuration number 19 (Table 1), where significant geo-referencing error existed, as noted above. Therefore, the delineated tree extents were transformed to fit the locations of respective trees. Readers can refer to Tu et al. (2019) for details on the GEOBIA method used. The tree crown delineation was applied to extract further information, for the individual trees. For each dataset, the following variables were extracted:

- tree height estimated using the maximum CHM value for each tree;

- the spectral mean, standard deviation of the NIR and NDVI bands;

- four Haralick texture grey level co-occurrence matrices (GLCMs) of the NIR and NDVI bands, where the GLCMs included standard deviation, homogeneity, dissimilarity, and contrast.

The extracted spectral and textural information was used for PPC estimation from multivariate linear regression ( $\mathrm{Tu}$ et al., 2019). Both the CHM-derived tree height and spectral-textural-data-derived PPC were compared to the TLS tree heights and field derived PPC, respectively to estimate the coefficient of determinations $\left(\mathrm{R}^{2}\right)$ and RMSE. The delineated tree extents for each dataset were also used to calculate zonal statistics of the photogrammetric point cloud to estimate the point cloud density within tree crowns. The point cloud density was normalised by dividing the point density by the square of the pixel GSD to allow analysis of the effect of other variables (i.e. average image area) in addition to pixel GSD, which has a known significant influence on the point cloud density (Dandois et al., 2015).

\subsection{Assessment of information quality extracted for individual trees} ing:

Several quality indicators were generated for further analysis, includ-

(1) the RMSE and acceptance percentage of the tie points, provided in the processing reports, as indicators of photo-alignment quality;

(2) normalised point cloud density of the point cloud densification quality;

(3) the $\mathrm{R}^{2}$ and RMSE of tree height estimation for evaluation of the reconstructed model accuracy; and

(4) and the $\mathrm{R}^{2}$ and RMSE of the PPC estimation.

Higher tie point acceptance signifies higher signal-to-noise ratio of tie points generated by the structure from motion (SfM) algorithm, whereas a lower tie point RMSE represents a higher tie point projection accuracy. Higher point cloud density means that more details in the tree crowns were reconstructed by the multi-view stereoscopic (MVS) densification algorithm (Novaković et al., 2017). Higher $\mathrm{R}^{2}$ values indicates that the image-derived tree structures (heights, PPCs) explain more of the variance of the field-measured tree heights, while 
lower RMSE of the image-derived tree structures means there is less error in the estimations. Fig. 1 shows the conceptual diagram of the experiment.

\subsection{Analysing the effect of image acquisition variables}

The image acquisition variables assessed included flight altitude, image side-lap, flying speed, flying direction, and solar elevation, which is denoted as variable set 1 . Solar elevation was derived from the flight time using the Solar Calculator WebApp (http://ausdesign.com. $\mathrm{au} / \mathrm{articles} / \mathrm{calc}$.html). These variables were selected because they are the 'configurable variables' for most flight planning software packages, except solar elevation. With the constraints of latitude and season, solar elevation can to some extent be controlled by selecting the time of the flight mission, which is important as several studies have found that solar elevation can significantly affect drone derived image results (Aasen et al., 2018; Dandois et al., 2015). The five flight variables were further segregated into eight, which is denoted as variable set 2 , where the altitude was removed and pixel GSD, image forward overlap, average image area, and average pitch angle were added. These were added because the pixel GSD is a function of altitude (when the focal length is a constant) and the forward overlap and average image area are the functions of pixel GSD, which are shown as follows:

$$
\begin{aligned}
& \mathrm{GSD}=\frac{\text { sensorsize }_{x} \cdot \text { altitude }_{\text {pixelnumbers }} \cdot \text { focallength }^{\text {foln }}}{\text { pensorsize }} \\
& =\frac{\text { sensorsize }_{y} \cdot \text { altitude }}{\text { pixelnumbers } \boldsymbol{A}_{y} \cdot \text { focallength }}
\end{aligned}
$$

$$
\begin{aligned}
\text { Averageimageavera }= & G^{2} \times \text { pixelnumber }_{x} \\
& \times \text { pixelnumber }_{y} \\
= & \text { sensorsize }_{x} \times \text { sensorsize }_{y} \\
& \times\left(\frac{\text { altitude }}{\text { focallength }}\right)^{2}
\end{aligned}
$$

Forwardoverlap $\%$

$=\left(1-\frac{\text { speed } \cdot \text { triggerspeed }}{G S D \cdot \text { pixelnumber }_{y}}\right) \times 100 \%$

$=\left(1-\frac{\text { speed } \bullet \text { triggerspeed } \bullet \text { focallength }}{\text { altitude } \bullet \text { sensorsize }}\right) \times 100 \%$

The pixel GSD was derived from the orthomosaic, where the viewing direction was ortho-rectified to nadir. It should be noted that

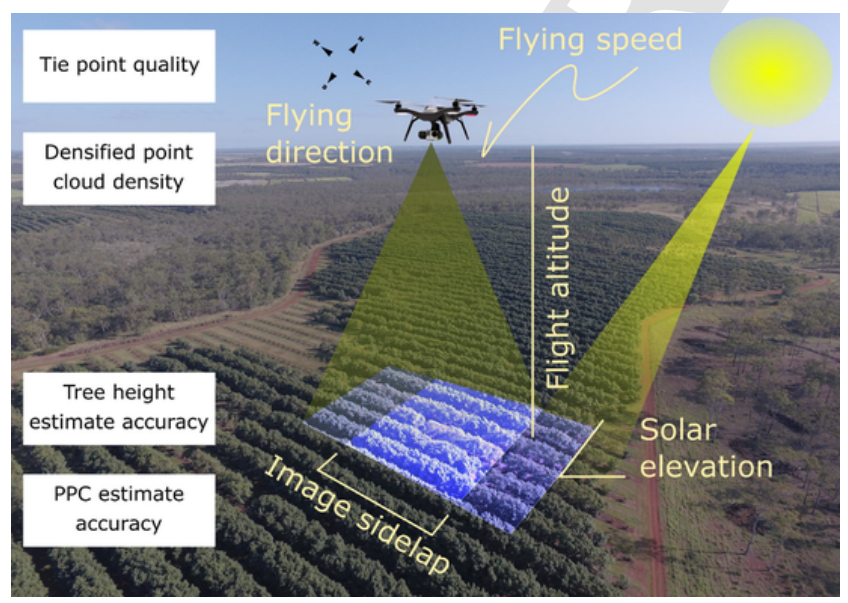

Fig. 1. Conceptual diagram of the research objective, which describes the independent (altitude, side-lap, speed, etc., written in yellow colour) and dependent (quality indicators mentioned above, representing the quality of each step of the workflow, shown in white boxes) variables of band interest. (For interpretation of the references to colour in this figure legend, the reader is referred to the web version of this article.) all pixels were squares in the orthomosaics, which made $\mathrm{GSD}_{\mathrm{x}}$ and $\mathrm{GSD}_{\mathrm{y}}$ the same average GSD in our case. The image forward overlap was derived based on both pixel GSD and the flying speed since the trigger speed of image acquisition was known. Average image area was derived by multiplying the number of pixels in the sensor plane by the square of pixel GSD. The average pitch angle was calculated using the calibrated image rotation matrix in Agisoft MetaShape Pro with a newly developed Python script, which was highly correlated with the flying speed.

The aforementioned two variable sets were used as independent variables, whilst the seven quality indicators mentioned in Section 2.5 were selected as dependent variables in the subsequent partial least square (PLS) regression analysis. The details of two independent variable sets and the dependent variables can be found in Table 2. We used PLS regression rather than analysis of variance (ANOVA) as the assumption of ANOVA is that the independent variables must be normally distributed. However, due to the restriction of available times for conducting drone missions (e.g., suitable illumination condition within one day), some of the variables, such as solar elevation, were not normally distributed. Also, there was multi-collinearity between some variables, e.g. between the average pitch angle and flying speed, and between pixel GSD, average image area, and image forward overlap. PLS is better equipped to analyse variables with multi-collinearity by projecting both the independent and dependent datasets to principal component spaces, while still maximising the covariance between independent and dependant datasets at the same time (Martens et al., 1986; Wold et al., 1984).

We used both the original five-variable set (variable set 1) and the extended eight-variable set (variable set 2) to run the PLS regression against each quality indicator individually (Table 2) and generated a prediction model for each variable set. Flying direction was converted from a categorical variable into three independent numerical variables using dummy coding (Cohen et al., 2014). Because the variables were in different units, they were standardised to unitless and centralised values before importing them into the PLS regressor. Cross validation was applied during the regression by using bootstrap subsets to remove insignificant variables and principal components one by one based on the models' RMSE. Once the final variable sets and the optimal principal component number were determined, we applied the optimal variable sets and principal component number to the regression and cal-

\begin{tabular}{|c|c|}
\hline $\begin{array}{l}\text { Independent } \\
\text { variables } \\
\text { (Flight variables) }\end{array}$ & $\begin{array}{ll}\text { Variable set 1: } & \text { Variable set 2: } \\
\text { - Flight altitude } & \text { - Image side-lap } \\
\text { - Image side-lap } & \text { - Flying speed } \\
\text { - Flying speed } & \text { - Flying direction } \\
\text { - Flying direction } & \text { - Solar elevation } \\
\text { - Solar elevation } & \text { - Pixel GSD } \\
& \text { - Average image area } \\
& \text { - Image forward overlap } \\
& \text { - Average image pitch }\end{array}$ \\
\hline $\begin{array}{l}\text { Dependent } \\
\text { variables } \\
\text { (Quality indicators) }\end{array}$ & $\begin{array}{l}\text { Photo alignment quality: } \\
\text { - RMSE of tie points } \\
\text { - Acceptance percentage of tie point } \\
\text { Point cloud quality: } \\
\text { - Normalised point cloud density } \\
\text { Tree height estimation accuracy: } \\
\text { - } \mathrm{R}^{2} \text { and RMSE of tree height estimation } \\
\text { PPC estimation accuracy: } \\
\text { - } \mathrm{R}^{2} \text { and RMSE of PPC estimation using NIR spectral- } \\
\text { textural data } \\
\text { - } \mathrm{R}^{2} \text { and RMSE of PPC estimation using NDVI spectral- } \\
\text { textural data }\end{array}$ \\
\hline
\end{tabular}
culated the significance of the multivariate correlation (sMC) based on the method proposed by Tran et al. (2014) to access the signifi-

Table 2

Input variables for the PLS regressions. Independent variables are the $\mathrm{X}$ term and dependent variables are the $\mathrm{Y}$ term in the regression formula. 
cance of each variable. The PLS regression workflow (Fig. 2) was achieved using an in-house Python script.

\subsection{Optimal flight plan simulation}

After establishing the PLS models, we used the models which had the highest coefficient of determination values to simulate optimal settings of flight planning variables. Some variables, which improved or declined all quality indicators, were fixed as constant values in the models. Three sets of simulated flights with different combinations of flight planning variables were imported into the prediction models based on three respective simulated scenarios:

The first scenario used the same setting as our experiment, with imagery captured with a fixed trigger speed of $1 \mathrm{~s}$. In this case, the pixel GSD, average image area, and image forward overlap changed according to the flight altitude.

The second scenario assumed the imagery was captured in a fixed forward overlap setting. In this case, the pixel GSD and average image area changed according to the flight altitude.

The third scenario assumed that the pixel GSD and image forward overlap were constant for all flight altitudes. Only the average image area changed according to the flight altitude in this case.

In each scenario, the GSD was set using the average GSD among all our flights which were conducted at the same altitude, and the average image area were calculated accordingly. The first scenario was designed based on the real situation that our flights were conducted, with the camera triggered using a fixed interval. In this case, the image forward overlap was also calculated accordingly based on the GSD and flying speed. The second scenario assumed the camera has been integrated to the pilot system and there is no I/O limit for writing files into the storage device. In this case, the images can be acquired based on precise waypoint locations to guarantee constant image forward overlap. The third scenario inherited the assumption of the second scenario, plus an additional assumption that at each altitude, different cameras were used to acquire the same GSD, and the sensor resolution was the only difference in specification between those cameras. The simulated flights allowed detailed interpretation of the impact of flight planning variables and identification of the optimal settings in different scenarios.

\section{Results}

In this section, the results are shown in two parts. Section 3.1 shows the PLS results for assessing the influence of drone flight planning variables on data quality. Section 3.2 shows the predicted optimal flight plans accordingly to three different flight scenarios using the best-explained PLS prediction models.

\subsection{The influence of flight variables on data quality}

The following models 1 and 2 represent the PLS regression model for variable sets 1 and 2, respectively. As the input variable sets were standardised, the magnitude and the sign of the regression coefficients of each variable were assumed to represent both the importance and the trend of influence of specific variables. For each regression of the quality indicators, the $\mathrm{R}^{2}$ values and the dominance of both models were displayed. The dominance of each variable was described as the percentage of each variable's regression coefficient over the sum of the absolute values of all regression coefficients of each quality indicator's regression model. Tables 3 and 4 provide a summary of the results of models 1 and 2, respectively. A positive impact of variables on tie point acceptance percentage, normalised point cloud density, and the $\mathrm{R}^{2}$ of tree height and PPC estimation means that increasing such variables improves the quality of resulting information. On the other hand, a negative impact of variables on various RMSE indicates that increasing such variables improves the data quality.

Based on the impacts of each quality indicator shown in Tables 3 and 4 , we can tell that model 2 had higher coefficient of determination on almost every quality indicator, which means it explained the variance of each indicator better than model 1. The image forward overlap was identified as the most dominant variable that had the most dominance for tie point acceptance, normalised cloud density, and NDVI PPC $\mathrm{R}^{2}$, and had positive impacts on almost all quality indicators, except for normalized tie point RMSE (Table 4). Solar elevation was yet another important variable, which had the most dominance for normalized tie point RMSE and NIR PPC estimation, and had positive impacts on almost all quality indicators, except for tree height estimation on which it had a weak but negative impact (Table 4). The influences of other drone flight planning variables are discussed in detailed below based on PLS regression model 2 (Table 4). If the $\mathrm{R}^{2}$ of models 1 and 2 were similar, both models were explained at the same time.

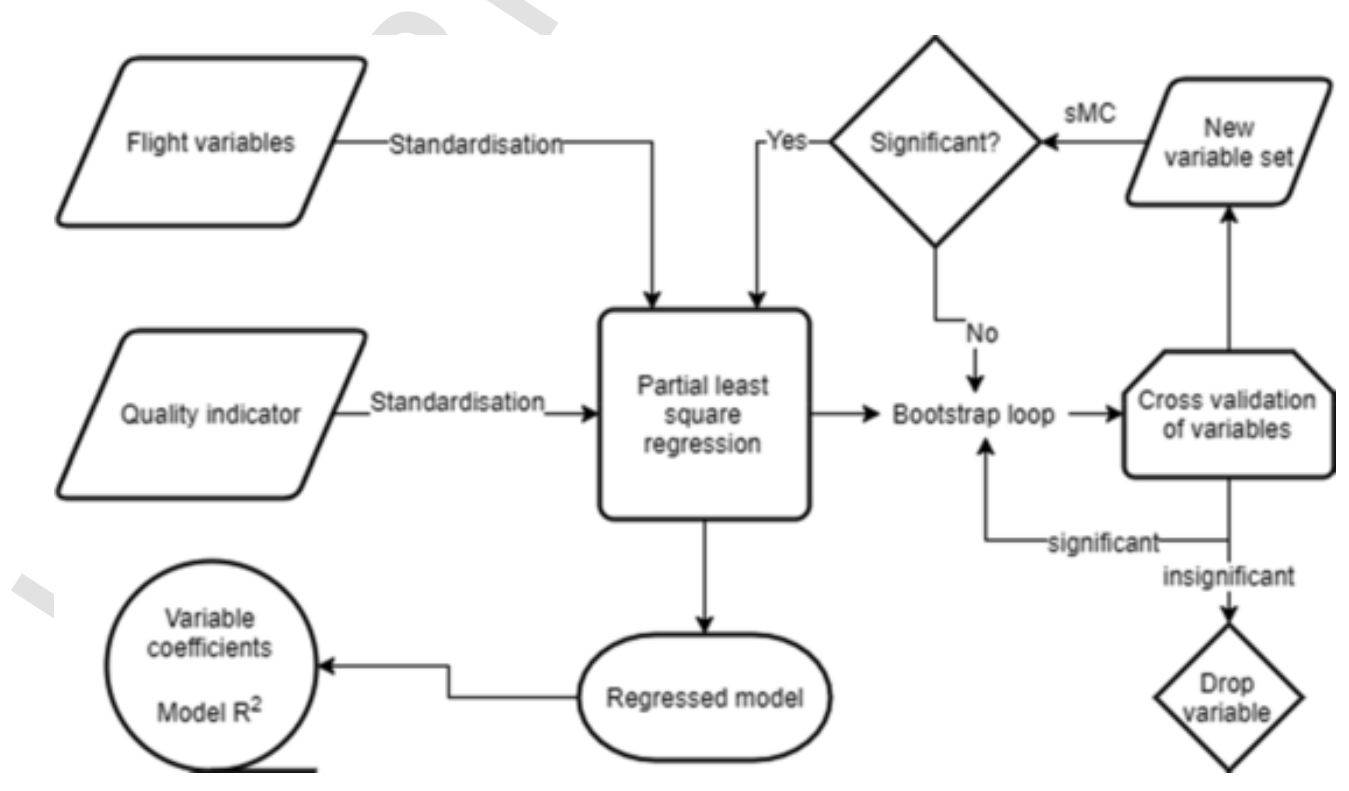

Fig. 2. The workflow of the partial least square regression in this study. 
Table 3

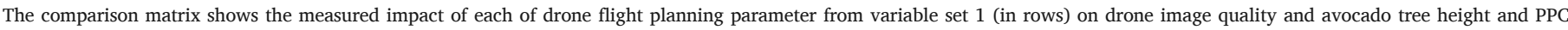

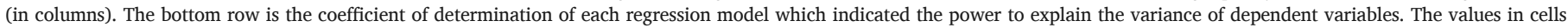

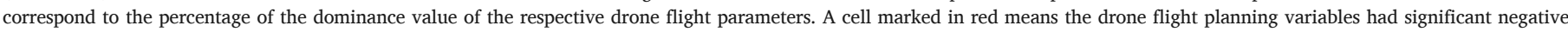

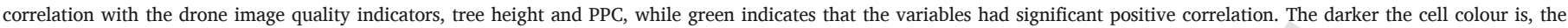
stronger influence the variables had on the image quality indicators. The blank cells mean the variables did not have significant influence on respective indicators.

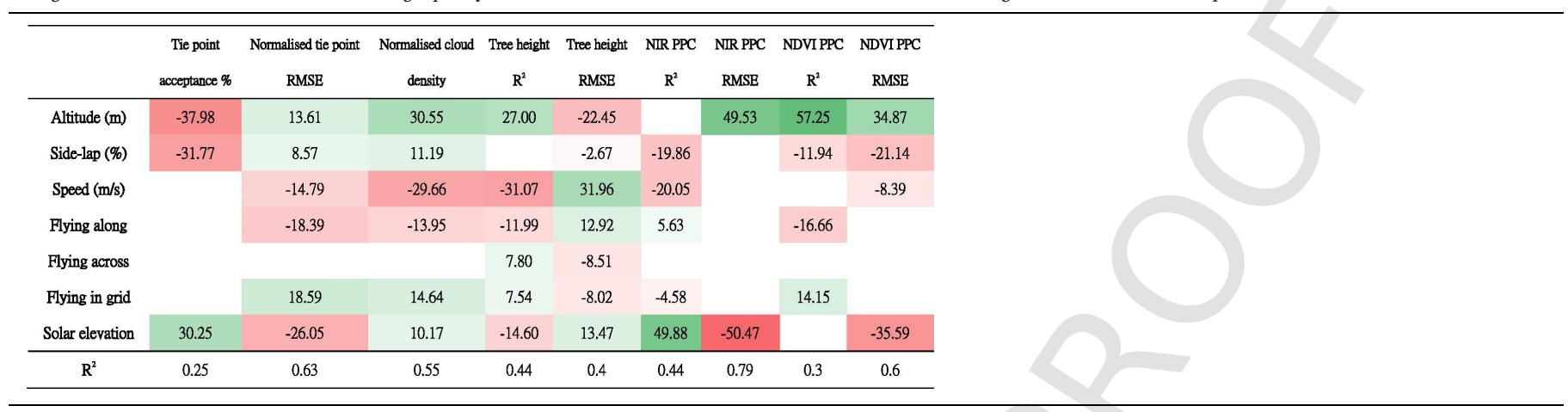

Table 4

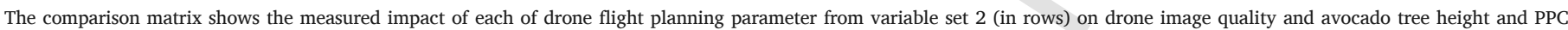

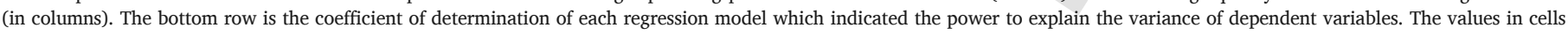

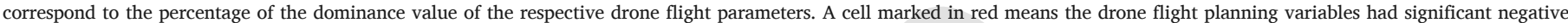

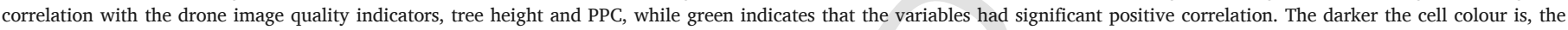
stronger influence the variables had on the image quality indicators. The blank cells mean the variables did not have significant influence on respective indicators.

\begin{tabular}{|c|c|c|c|c|c|c|c|c|c|c|}
\hline & $\begin{array}{c}\text { Tie point } \\
\text { acceptance \% }\end{array}$ & $\begin{array}{c}\text { Normalised tie point } \\
\text { RMSE }\end{array}$ & $\begin{array}{c}\text { Normalised cloud } \\
\text { density }\end{array}$ & $\begin{array}{c}\text { Tree height } \\
\text { R2 }\end{array}$ & $\begin{array}{c}\text { Tree height } \\
\text { RMSE }\end{array}$ & $\begin{array}{c}\text { NIR PPC } \\
\quad \text { R2 }\end{array}$ & $\begin{array}{l}\text { NIR PPC } \\
\text { RMSE }\end{array}$ & $\begin{array}{c}\text { NDVI PPC } \\
\text { R2 }\end{array}$ & $\begin{array}{c}\text { NDVI PPC } \\
\text { RMSE }\end{array}$ & 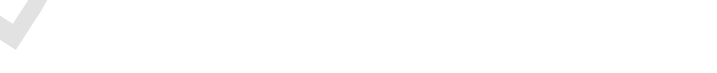 \\
\hline Side-lap (\%) & -12.37 & 9.86 & 10.67 & -0.82 & -0.98 & -19.72 & & & -27.47 & \\
\hline Speed $(\mathrm{m} / \mathrm{s})$ & & & & 11.11 & -10.11 & -9.34 & & & & \\
\hline Flying along & & & & 0.07 & 0.17 & 8.54 & & & & \\
\hline Flying across & & & & -0.07 & -0.13 & & & & & \\
\hline Flying in grid & & 23.53 & & -0.01 & -0.08 & -4.90 & & & & \\
\hline Solar elevation & 16.24 & -42.78 & 10.17 & -2.42 & 1.76 & 41.43 & -50.82 & & -35.33 & \\
\hline Pixel GSD (cm) & -20.63 & & 7.18 & -32.86 & 34.23 & & 26.90 & 49.31 & & \\
\hline Forward overlap (\%) & 32.11 & 23.83 & 52.43 & 27.29 & -29.21 & & & 50.69 & & \\
\hline Average image area $\left(\mathrm{m}^{2}\right)$ & -18.66 & & -18.13 & 21.11 & -19.85 & & 22.28 & & 37.21 & \\
\hline Average pitch & & & -1.42 & -4.23 & 3.46 & -16.07 & & & & \\
\hline $\mathbf{R}^{2}$ & 0.41 & 0.69 & 0.92 & 0.93 & 0.91 & 0.44 & 0.79 & 0.37 & 0.62 & \\
\hline
\end{tabular}

\subsubsection{The effect of flight altitude}

As we mentioned above, changing the flight altitude not only changes the pixel GSD but also the average image area and image forward overlap (using a camera with fixed trigger speed) at the same time. Combinations of sub-variables sometimes cause contradictions regarding the data quality. Regarding the tie point acceptance percentage, image forward overlap was the dominant variable of the tie point acceptance percentage. Pixel GSD and average image area were the second most dominant variables as the importance of each was about 1.6 times less than forward overlap in the opposite direction of correlation (Table 4). This means that if changing altitude does not change the forward overlap, decreasing altitude itself decreases the GSD and average image area, and thus improves the tie point quality because the GSD has higher dominance than the average image area. The overall impacts on tie point quality was an increase of the tie point acceptance percentage $\left(R^{2}=0.41\right)$, while the tie point RMSE $\left(R^{2}=0.69\right)$ was not affected (Table 4). The effect of decreasing altitude on point cloud density, apart from the effect of pixel GSD, was generally negative $\left(R^{2}=0.92\right)$. According to Eqs. (1)-(3), pixel GSD and average image area are functions of altitude, and forward overlap is the function of both altitude and speed. As the dominance of average image area is more than twice as large as pixel GSD, decreasing altitude decreases the normalised point cloud density, possibly due to the tie point limit settings in image pre-processing (see Section 2.4). This point cloud decrease can even be amplified if changing altitude changes forward overlap, as forward overlap is the most dominant variable in the model (Table 4). Regarding the effect on tree height estimation, both $\mathrm{R}^{2}$ and RMSE need to be evaluated. Both PLS models, assessing the $\mathrm{R}^{2}$ $\left(\mathrm{R}^{2}=0.93\right)$ and RMSE $\left(\mathrm{R}^{2}=0.91\right)$ of tree height, agreed that pixel GSD was the most important variable with the largest impact on three height estimates, followed by forward overlap and average image area (Table 4). Decreasing pixel GSD (higher image spatial resolution) increased the $\mathrm{R}^{2}$ and decreased the RMSE at the same time, which is desirable for tree height estimation. On the other hand, forward overlap and average image area were the second and third most important variables in both PLS models, which were 1.2 and 1.6 times less dominant than pixel GSD on $\mathrm{R}^{2}$ with positive correlation, and 1.2 and 1.7 times less dominant than pixel GSD on RMSE with negative correlation. This means that when changing altitude, the effect of changing pixel GSD and average image area almost offsets each other, making the overall influence on tree height estimation small. When considering the for- 
ward overlap as a function of altitude, flying higher can improve tree height estimation, as it increases the forward overlap and average image area, with the overall effect of these two variables being equivalent or even more important than decreasing the pixel GSD (Table 4). Finally, the effect of altitude on the estimation of PPC depends on whether NIR or NDVI is used (see Section 2.6). If PPC is derived from the NIR-based information, the change of altitude does not affect the $\mathrm{R}^{2}$ significantly $\left(\mathrm{R}^{2}=0.44\right)$, but RMSE decreases as altitude decreases $\left(\mathrm{R}^{2}=0.79\right)$. This is because altitude in model 1 and pixel GSD and average image area in model 2 all had positive coefficients (Tables 3 and 4), which mean that the higher the altitude is, the higher the RMSE. On the other hand, if PPC is estimated using NDVI-based information, then both models agreed that higher altitude increased the $\mathrm{R}^{2}\left(\mathrm{R}^{2}=0.3\right.$ and 0.37 for models 1 and 2, respectively) but increased the RMSE $\left(\mathrm{R}^{2}=0.6\right.$ and 0.62 for models 1 and 2, respectively) at the same time (Tables 3 and 4).

\subsubsection{The effect of image side-lap}

The effect of image side-lap on data quality was not as pronounced as flight altitude in most of the cases. A smaller image side-lap improved tie point quality, as it increased the tie point acceptance percentage $\left(\mathrm{R}^{2}=0.41\right)$ and decreased tie point RMSE $\left(\mathrm{R}^{2}=0.69\right)$, though it was the least dominant variable in the PLS models (Table 4). Both models 1 and 2 agreed that image side-lap was the third most dominant variable in predicting NIR-derived PPC $\mathrm{R}^{2}\left(\mathrm{R}^{2}=0.44\right.$ for both models 1 and 2) and NDVI-derived PPC RMSE $\left(\mathrm{R}^{2}=0.6\right.$ and 0.62 for models 1 and 2, respectively in Tables 3 and 4). Changing the image side-lap affected the estimation of PPC differently when using either the NIR or NDVI method. Decreasing image side-lap increased the $\mathrm{R}^{2}$ of NIR-derived PPC, while it increased the RMSE of NDVI-derived PPC. Image side-lap was also the third most dominant variable for predicting the normalised point cloud density $\left(\mathrm{R}^{2}=0.92\right)$ with the importance being five times smaller than forward overlap (Table 4). The trend of its influence on normalised point cloud density was opposite to the estimation of PPC using the NIR method, i.e., the higher the side-lap, the higher the normalised point cloud density. Therefore, to achieve an optimised balance between the point cloud density and PPC estimation, the image side-lap should be between $60 \%$ and $90 \%$.

\subsubsection{The effect of flight direction}

The flight direction had little effect on most of the dependent variables, except for the tie point RMSE, where both models 1 and 2 agreed that flying in a grid pattern increased the RMSE $\left(\mathrm{R}^{2}=0.25\right.$ and 0.41 for models 1 and 2, respectively. See Tables 3 and 4). The above observation suggested that flying a grid pattern increases the error of tie points in the SfM process. The effect of flying in a grid pattern on the tie points also reduced the accuracy of estimating tree height and PPC, but only to a limited extent as most of the poor-quality tie points were filtered out during the pre-processing. Flying direction was also one of the dominant variables for predicting the $\mathrm{R}^{2}$ of NIR-derived PPC $\left(\mathrm{R}^{2}=0.44\right.$ for both models 1 and 2$)$, which was five times and three times less dominant than the solar elevation in model 1 and 2, respectively (Tables 3 and 4). Both models agreed that flying along the row increased the $\mathrm{R}^{2}$ of estimating NIR-derived PPC, while flying in a grid pattern decreased the $R^{2}$. Flying along the row increased both the $R^{2}$ $\left(\mathrm{R}^{2}=0.93\right)$ and RMSE $\left(\mathrm{R}^{2}=0.91\right)$ at the same time for estimating tree height, while flying across the row and in a grid pattern reduced the $\mathrm{R}^{2}$ and RMSE for estimating tree height. However, such influence was negligible, as the total dominance of flight direction was 219 times less than that of the pixel GSD on the $\mathrm{R}^{2}$ and 90 time less than that of pixel GSD on the RMSE (Table 4). From the above observation, we can conclude that flying along the hedgerows generally improved the data quality, while flying in a grid pattern resulted in slightly poorer data quality, as flying along the row provided higher $\mathrm{R}^{2}$ for estimating PPC using the NIR method.

\subsubsection{The effect of flying speed}

The flying speed caused a change to the forward overlap as the camera trigger speed was fixed (Equation (3)). It also changed the average image pitch angles (Fig. 3), as the camera was mounted without a gimbal. Therefore, it appeared in model 1 that the flying speed had dominant influences on several quality indicators (i.e., tie point quality, point cloud density) (Table 3) but only had small dominances on the estimation of tree height and the $\mathrm{R}^{2}$ of NIR-derived PPC in model 2 (Table 4). The actual cause of the presumed influence of flying speed on data quality in model 1 came from either image forward overlap or average pitch angle in model 2 , which had higher $\mathrm{R}^{2}$ for the regression model for most of the quality indicators (Tables 3 and 4). Therefore, the influence of speed itself on data quality is addressed first. Subsequently, we will look into the influences of forward overlap and average image pitch angle.

A high flying speed is known to cause motion blur (Roth et al., 2018). Hence, we can consider the image quality as a function of flying speed so that the influence of flying speed on data quality can be explained as the influence of image quality. Interestingly, PLS model 2 (Table 4) showed that flying with a higher speed increased the $R^{2}\left(R^{2}=0.93\right)$ and decreased the RMSE $\left(R^{2}=0.91\right)$ for estimating tree height. This may be because we can easily filter out poor-quality (blurred) images for flights with high flying speed, improving the overall image quality. However, both models also agreed that a higher flying speed decreased the $\mathrm{R}^{2}$ of NIR-based PPC estimation, which were 2.5 times and 4.4 times less dominant than the most dominant variable (the solar elevation) in models 1 and 2 , respectively $\left(R^{2}=0.44\right.$. See Tables 3 and 4 ). This could be due to brightness variations between images, increasing with lower image forward overlap when the flying speed is high, causing poor performance of the colour balancing function, as the histograms of pixel values between images become very different (Tu et al., 2018). Higher forward overlap generally provided better data quality in model 2, i.e., higher tie point acceptance $\left(R^{2}=0.41\right)$ and normalised point cloud density $\left(R^{2}=0.92\right)$, more accurate tree height estimation $\left(R^{2}=0.93\right.$ for the model of $R^{2}$, and $\mathrm{R}^{2}=0.91$ for the model of RMSE), and higher $\mathrm{R}^{2}$ of PPC estimation using the NDVI method $\left(\mathrm{R}^{2}=0.37\right)$, though it increased the tie point RMSE at the same time $\left(\mathrm{R}^{2}=0.69\right)$. The PLS model 2 shows that forward overlap is either the most or the second most dominant variable in all the influencing quality indicators (Table 4). Higher image pitch angle generally caused poorer data quality on normalised point cloud density $\left(R^{2}=0.92\right)$, tree height estimation $\left(R^{2}=0.93\right.$ for the model of $\mathrm{R}^{2}$ and $\mathrm{R}^{2}=0.91$ for the model of RMSE), and the $\mathrm{R}^{2}$ of PPC estimation using the NIR method $\left(\mathrm{R}^{2}=0.44\right)$. However, the domi-

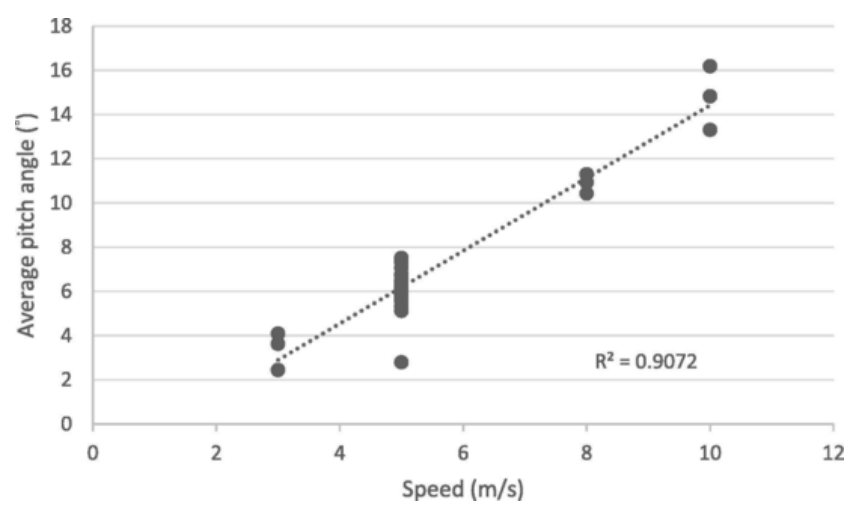

Fig. 3. The scatter plot of flying speed versus average image pitch angle. It shows a high correlation $\left(R^{2}=0.9\right)$ between these two variables when photos are captured without a gimbal. 
nances were small, except for the $\mathrm{R}^{2}$ for estimating PPC using the NIR method, which had a dominance that was only 2.6 times smaller than the most dominant variable (the solar elevation) and similar to that of the second most dominant variable (image side-lap) (Table 4).

\subsubsection{The effect of solar elevation}

Drone campaigns in previous studies usually only consider the illumination condition within one day (Aasen et al., 2018), and generally illumination around solar noon is considered the best for creating high contrast and optimise results. The influences of solar elevation on data quality is usually being ignored as it cannot be controlled precisely. We found that solar elevation generally had significant influences on all quality indicators, except for the $\mathrm{R}^{2}$ of PPC estimation using the NDVI method (Table 4). Higher solar elevation provided higher tie point acceptance $\left(R^{2}=0.41\right.$, half the dominance of forward overlap), lower tie point RMSE $\left(\mathrm{R}^{2}=0.69\right.$, the most dominant variable), higher normalised point cloud density $\left(\mathrm{R}^{2}=0.92\right.$, five times less dominant than forward overlap), and more accurate PPC estimation using both the NIR (the most dominant variable, $\mathrm{R}^{2}=0.44$ for the model of $\mathrm{R}^{2}$ and $\mathrm{R}^{2}=0.79$ for the model of RMSE) and NDVI methods $\left(\mathrm{R}^{2}=0.62\right.$ for the model of RMSE, similar dominance to average image area but with opposite direction of correlation). However, a higher solar elevation reduced the accuracy of estimating tree height, though the influence of the solar elevation was negligible due to the small dominances. It is possibly that when the solar elevation was above 80 degree, the image contrast within the avocado tree canopy area was reduced, which decreased the selection of tie points used for the SfM algorithm.

\subsection{Optimal settings for tree crop structure measurements}

From the above results, the following facts can be summarised:

Flying along the hedgerow improved the data quality;

Smaller image pitch angle improved the data quality;

The effect of flying speed is uncertain for the tested global shutter camera; and

Higher solar elevation improved the data quality in general.

To establish optimal settings for acquisition of multi-spectral drone imagery for structural measurements of avocado tree crops, we can make the above four variables constant and create simulated flights with various combinations of other variables to predict the data quality using PLS model 2. We set the flying direction to along hedgerow and assumed the camera was mounted with a gimbal to keep the image pitch angle to 0 for all the simulated flights. Flying speed was set at $5 \mathrm{~m} / \mathrm{s}$ as most of the input datasets were collected at this speed. Solar elevation was set to $61.8^{\circ}$ since it was the median solar elevation between 9:00 and 16:00 on 4 February 2017, and the same time range as the experiment conducted by Dandois et al. (2015). Nevertheless, the variables were standardised before importing them into the regression model, so that all the constant variables became the same unitless value. The simulations were conducted for three types of flight planning scenarios stated in Section 2.9 and below.

\subsubsection{Optimal setting for Scenario 1}

The first scenario used the same setting as our experiment, with imagery captured with a fixed camera trigger speed at $1 \mathrm{~s}$. In this case, the pixel GSD, average image area, and image forward overlap changed according to the flight altitude. Table 5 shows the combinations of variables of the simulated flights in Scenario 1, while Fig. 4 shows the simulated quality for each indicator.

The ideal situation is that all the bars of non-RMSE indicator in the figure for a specific simulated flight are large positive values,
Table 5

Variables of simulated flights for Scenario 1.

\begin{tabular}{llllll}
\hline $\begin{array}{l}\text { Simulated } \\
\text { No. }\end{array}$ & $\begin{array}{l}\text { Altitude } \\
\text { (m) }\end{array}$ & $\begin{array}{l}\text { Side- } \\
\text { lap } \\
\text { (\%) }\end{array}$ & $\begin{array}{l}\text { pixel } \\
\text { GSD } \\
\text { (cm) }\end{array}$ & $\begin{array}{l}\text { Forward } \\
\text { overlap (\%) }\end{array}$ & $\begin{array}{l}\text { Average image } \\
\text { area (m) })\end{array}$ \\
\hline $\mathbf{1}$ & 100 & 90 & 9.796667 & 94.68357 & 11793.37 \\
$\mathbf{2}$ & 100 & 80 & 9.796667 & 94.68357 & 11793.37 \\
$\mathbf{3}$ & 100 & 70 & 9.796667 & 94.68357 & 11793.37 \\
$\mathbf{4}$ & 100 & 60 & 9.796667 & 94.68357 & 11793.37 \\
$\mathbf{5}$ & 75 & 90 & 7.183333 & 92.74942 & 6340.642 \\
$\mathbf{6}$ & 75 & 80 & 7.183333 & 92.74942 & 6340.642 \\
$\mathbf{7}$ & 75 & 70 & 7.183333 & 92.74942 & 6340.642 \\
$\mathbf{8}$ & 75 & 60 & 7.183333 & 92.74942 & 6340.642 \\
$\mathbf{9}$ & 50 & 90 & 4.796667 & 89.14177 & 2827.224 \\
$\mathbf{1 0}$ & 50 & 80 & 4.796667 & 89.14177 & 2827.224 \\
$\mathbf{1 1}$ & 50 & 70 & 4.796667 & 89.14177 & 2827.224 \\
$\mathbf{1 2}$ & 50 & 60 & 4.796667 & 89.14177 & 2827.224 \\
$\mathbf{1 3}$ & 25 & 80 & 2.272 & 77.076 & 634.3046 \\
$\mathbf{1 4}$ & 25 & 70 & 2.272 & 77.076 & 634.3046 \\
$\mathbf{1 5}$ & 25 & 60 & 2.272 & 77.076 & 634.3046 \\
\hline
\end{tabular}

while RMSE indicators are large negative values, which is absent in the case. Therefore, we selected the optimal variable set by achieving the optimised balance between the tie point quality, normalised point cloud density, and tree height and PPC estimation accuracies. Simulated flight numbers 1-4 had the highest RMSE of estimating PPC and low acceptance percentage of tie points. Simulated flight numbers 13-15 had the lowest normalised point cloud density and the least accurate tree height estimation. In this case, simulated flight numbers 10 and 11, which were set to $50 \mathrm{~m}$ flight altitude and $80 \%$ and $70 \%$ image side-lap, respectively, were selected as the optimal settings. These settings had overall average point cloud density but higher accuracy for estimating tree height and NIR-PPC estimation compared to flight numbers 5-8. Reducing flight altitude further will decrease image forward overlap below the $80 \%$ threshold and hence significantly reduce the data quality.

\subsubsection{Optimal setting for Scenario 2}

The second scenario assumed the imagery was captured in a fixed forward overlap setting. The image forward overlap was set at $80 \%$, which corresponds to the threshold suggested by Dandois et al. (2015). In this case, the pixel GSD and average image area changed according to the flight altitude. Table 6 shows the combinations of variables of the simulated flights in Scenario 2, while Fig. 5 shows the simulated quality measures of each indicator.

In this case, simulated flight numbers 13 or 14 , which had an altitude of $25 \mathrm{~m}$ and $80 \%$ and $70 \%$ image side-lap, were chosen as the optimal flight plans, as they had not only the highest accuracy of tree height and NIR-PPC estimation, but also the highest tie points quality and average point cloud density. Theoretically, the lower altitude provides a higher accuracy of the tree height estimation and a lower RMSE of the PPC estimation according to the trend shown in Fig. 5. However, a lower altitude also increased the required time to finish a mission due to a smaller imaged area per photo. Therefore, in a practical situation, the optimal flight altitude still depends on the drone battery performance and the requirement of data accuracy.

\subsubsection{Optimal setting for Scenario 3}

The third scenario assumed that the pixel GSD and image forward overlap were constant for all flight altitudes. This is based on the assumption that at each altitude, different cameras were used to acquire the same GSD, and the sensor resolution was the only difference in the specifications between those cameras. Only the average image 

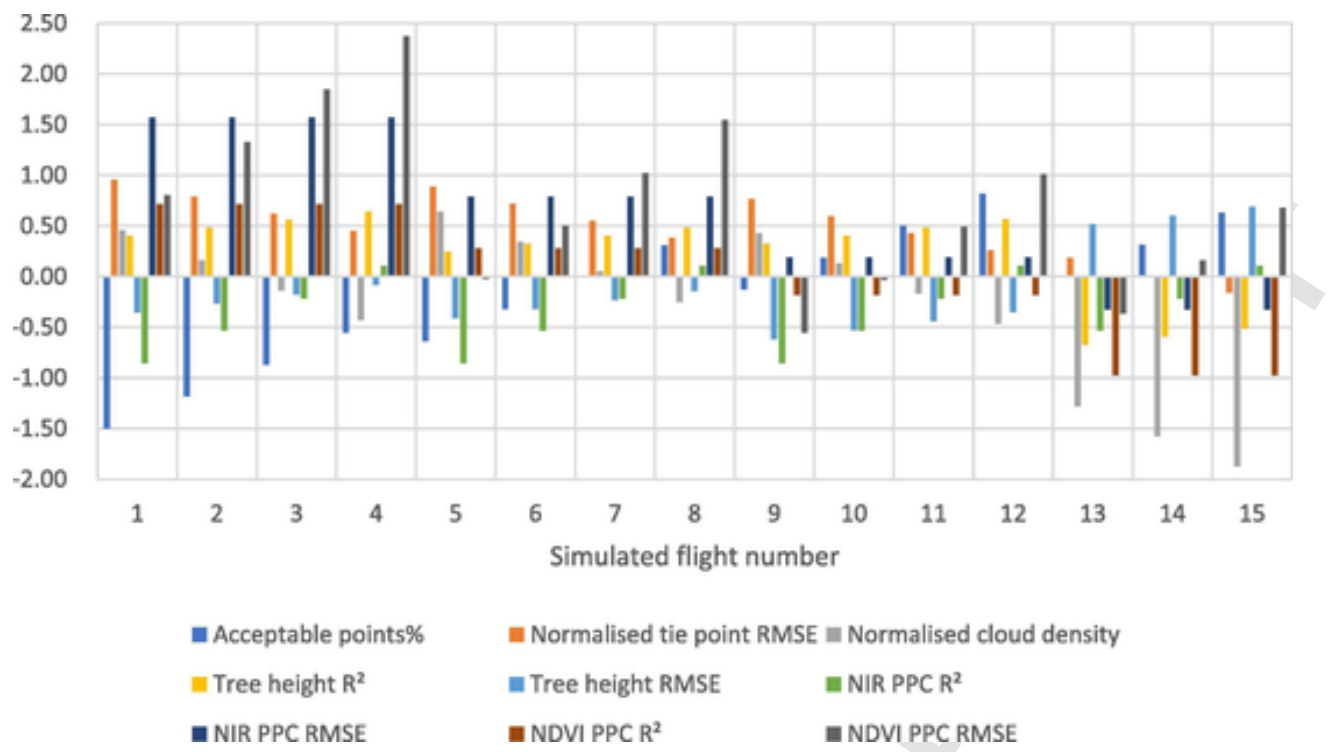

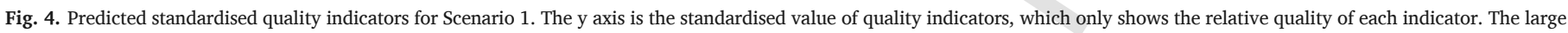
positive values of non-RMSE indicators represent better data quality, while the large negative values of RMSE indicators represent better data quality.

Table 6

Variables of simulated flights for Scenario 2.

\begin{tabular}{llllll}
\hline $\begin{array}{l}\text { Simulated } \\
\text { No. }\end{array}$ & $\begin{array}{l}\text { Altitude } \\
(\mathbf{m})\end{array}$ & $\begin{array}{l}\text { Side- } \\
\text { lap } \\
\mathbf{( \% )}\end{array}$ & $\begin{array}{l}\text { pixel } \\
\text { GSD } \\
(\mathbf{c m})\end{array}$ & $\begin{array}{l}\text { Forward } \\
\text { overlap (\%) }\end{array}$ & $\begin{array}{l}\text { Average image } \\
\text { area (m) })\end{array}$ \\
\hline $\mathbf{1}$ & 100 & 90 & 9.796667 & 80 & 11793.37 \\
$\mathbf{2}$ & 100 & 80 & 9.796667 & 80 & 11793.37 \\
$\mathbf{3}$ & 100 & 70 & 9.796667 & 80 & 11793.37 \\
$\mathbf{4}$ & 100 & 60 & 9.796667 & 80 & 11793.37 \\
$\mathbf{5}$ & 75 & 90 & 7.183333 & 80 & 6340.642 \\
$\mathbf{6}$ & 75 & 80 & 7.183333 & 80 & 6340.642 \\
$\mathbf{7}$ & 75 & 70 & 7.183333 & 80 & 6340.642 \\
$\mathbf{8}$ & 75 & 60 & 7.183333 & 80 & 6340.642 \\
$\mathbf{9}$ & 50 & 90 & 4.796667 & 80 & 2827.224 \\
$\mathbf{1 0}$ & 50 & 80 & 4.796667 & 80 & 2827.224 \\
$\mathbf{1 1}$ & 50 & 70 & 4.796667 & 80 & 2827.224 \\
$\mathbf{1 2}$ & 50 & 60 & 4.796667 & 80 & 2827.224 \\
$\mathbf{1 3}$ & 25 & 80 & 2.272 & 80 & 634.3046 \\
$\mathbf{1 4}$ & 25 & 70 & 2.272 & 80 & 634.3046 \\
$\mathbf{1 5}$ & 25 & 60 & 2.272 & 80 & 634.3046 \\
\hline
\end{tabular}

area changed according to the flight altitude in this case. Table 7 shows the combinations of variables of the simulated flights in Scenario 3, while Fig. 6 shows the simulated quality measure of each indicator.

The results show that if the camera can achieve the same spatial resolution at any given flight altitudes (using lenses with different focal lengths or simply different cameras), it can produce higher estimation accuracy of tree height, when the flight altitude is high. However, higher altitude also decreased the accuracy of estimating PPC (mainly higher RMSE). Therefore, among the four selected flight altitude, $75 \mathrm{~m}$ was chosen to be the optimal flight altitude that achieves second highest tree height accuracy as well as average NIR-PPC RMSE and point cloud density. The image side-lap suggestion is similar to Scenario 2, which should be set between $70 \%$ and $80 \%$ to achieve a balance between point cloud density and the accuracy of PPC estimation.

\section{Discussion}

The proposed workflow was designed for the camera specification of the multi-spectral Parrot Sequoia ${ }^{\circledR}$ camera, so that the suggestions such as flight altitude and image side-lap may not be applied directly to other sensors. Nevertheless, the proposed procedure of optimisation evaluation is still applicable to other workflows that work with other cameras. The workflow for measuring tree crops may also vary depending on the specification of different cameras. As the pixel GSD in our datasets ranged between 0.02 and $0.1 \mathrm{~m}$, the best way to estimate the plant-scale was to use spectral-textural information for regression. However, new algorithms to estimate PPC may be developed for finer spatial resolution imagery. For instance, the PPC estimation may be determined solely based on the spatial information (e.g. photogrammetric point cloud structure) extracted from the imagery so that the accuracy of the radiometric correction may become less important, if tree crops structure or condition are the only attributes required by the users. Nevertheless, for the purposes of estimating the capacity of photosynthesis and transpiration and even species classification in horticulture or silviculture, radiometrically corrected imagery is still necessary (Nevalainen et al., 2017; Saari et al., 2011; Sellers, 1987). Hence, the use of the multi-spectral Parrot Sequoia camera, which has been used in many studies (Aasen et al., 2018; Deng et al., 2018), provides a one-go solution to take full advantage of the spectral information and saves the trouble for repeated data acquisition and processing using different types of sensors (i.e., RGB and multi-spectral cameras).

This study focused on determining optimal flight planning settings, considering data quality in terms of photo alignment, point cloud densification, and the estimations of tree height and PPC. However, factors such as flight duration and processing time were not taken into consideration. For example, based on the analysis, the simulated flights in Scenario 2 (Section 3.2.2) suggested that lower flying altitude increased the data quality. On the other hand, flying at low altitude increases the required flight duration to cover the same area and lengthen the processing time because of the smaller pixel size and larger number of pixels. Seifert et al. (2019) suggested that the flight duration was linearly related to the flight altitude, but that the processing time was non-linear. However, such non-linear correlation between processing time and sensor resolution was not directly related at higher altitude in their study. Their finding regarding the processing time matches our suggestion in 3.2.3 that flying higher with a higher-resolution camera may provide not only higher-quality results but also higher efficiency.

Dandois et al. (2015) considered a flying altitude of $80 \mathrm{~m}$ to be optimal based on image collection and processing efficiency for map- 


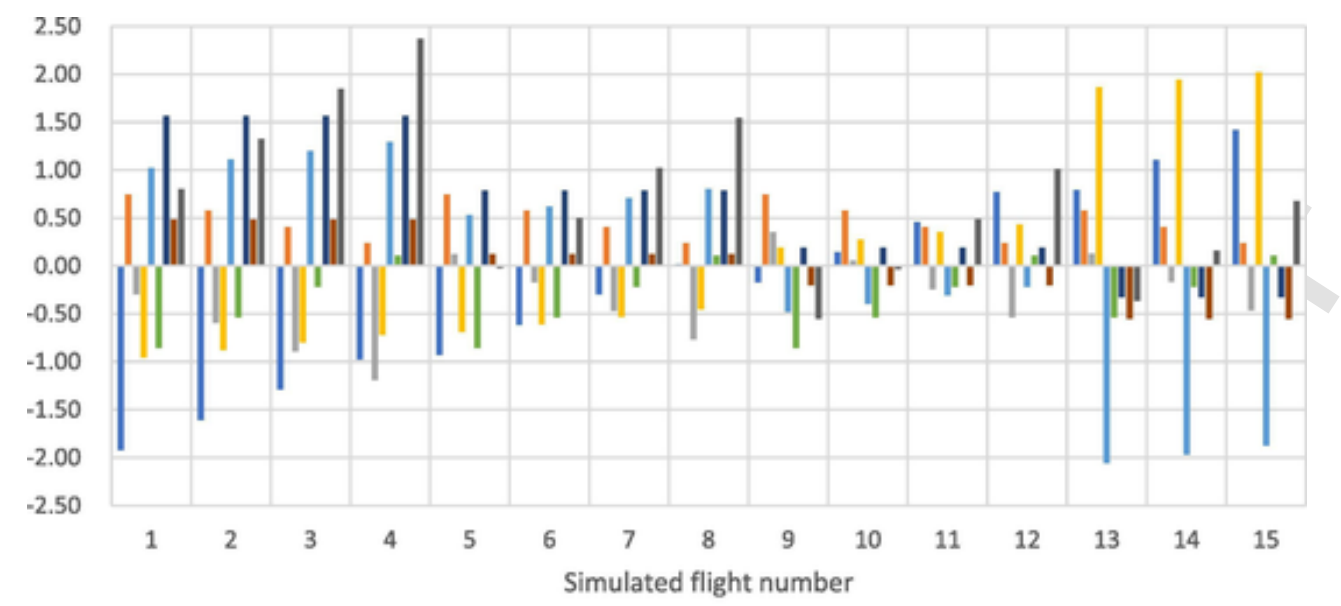

\begin{tabular}{|c|c|}
\hline acceptable points\% & $\equiv$ Normalised tie point RMSE $\equiv$ Normalised cloud density \\
\hline wree height $\mathrm{R}^{2}$ & = Tree height RMSE \\
\hline EIR PPC RMSE & = NDVI PPC RMSE \\
\hline
\end{tabular}

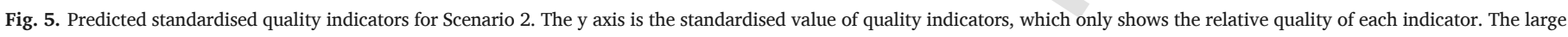
positive values of non-RMSE indicators represent better data quality, while the large negative values of RMSE indicators represent better data quality.

Table 7

Variables of simulated flights for Scenario 3.

\begin{tabular}{llllll}
\hline $\begin{array}{l}\text { Simulated } \\
\text { No. }\end{array}$ & $\begin{array}{l}\text { Altitude } \\
(\mathbf{m})\end{array}$ & $\begin{array}{l}\text { Side- } \\
\text { lap } \\
\text { (\%) }\end{array}$ & $\begin{array}{l}\text { pixel } \\
\text { GSD } \\
(\mathbf{c m})\end{array}$ & $\begin{array}{l}\text { Forward } \\
\text { overlap (\%) }\end{array}$ & $\begin{array}{l}\text { Average image } \\
\text { area (m } \mathbf{~}^{\mathbf{}} \text { ) }\end{array}$ \\
\hline $\mathbf{1}$ & 100 & 90 & 2.272 & 80 & 11793.37 \\
$\mathbf{2}$ & 100 & 80 & 2.272 & 80 & 11793.37 \\
$\mathbf{3}$ & 100 & 70 & 2.272 & 80 & 11793.37 \\
$\mathbf{4}$ & 100 & 60 & 2.272 & 80 & 11793.37 \\
$\mathbf{5}$ & 75 & 90 & 2.272 & 80 & 6340.642 \\
$\mathbf{6}$ & 75 & 80 & 2.272 & 80 & 6340.642 \\
$\mathbf{7}$ & 75 & 70 & 2.272 & 80 & 6340.642 \\
$\mathbf{8}$ & 75 & 60 & 2.272 & 80 & 6340.642 \\
$\mathbf{9}$ & 50 & 90 & 2.272 & 80 & 2827.224 \\
$\mathbf{1 0}$ & 50 & 80 & 2.272 & 80 & 2827.224 \\
$\mathbf{1 1}$ & 50 & 70 & 2.272 & 80 & 2827.224 \\
$\mathbf{1 2}$ & 50 & 60 & 2.272 & 80 & 2827.224 \\
$\mathbf{1 3}$ & 25 & 80 & 2.272 & 80 & 634.3046 \\
$\mathbf{1 4}$ & 25 & 70 & 2.272 & 80 & 634.3046 \\
$\mathbf{1 5}$ & 25 & 60 & 2.272 & 80 & 634.3046 \\
\hline
\end{tabular}

ping forest structure, as their study did not find significant influence of flight altitude on absolute location accuracy of the photogrammetric point cloud. As we discussed in Section 3.1.1, the influences of pixel GSD and average image area on the accuracy of tree height estimation partly offset each other. Such offset may be the reason that made the overall influence of flying altitude on tree height estimation small in the previous study if changing altitude does not involve changing forward overlap (Table 4). The study by Seifert et al. (2019) suggested that flying lower increases the accuracy of the photogrammetric point cloud, but the reason behind this is because the image forward overlap changed according to the altitude in their experiment, which is also the case of Scenario 1 (see Section 3.2.1). Therefore, higher point cloud RMSE is expected when the altitude is higher (Table 4). However, findings like these will depend on the types of trees, their height and canopy structure. From the results we showed in Section 3.2.2, we can tell that flying lower theoretically improves the accuracy of image-derived tree height, as the pixel GSD has a more dominating effect than the average image area on the regression model. Improvements in the accuracy of mapped tree height caused by higher image spatial resolu- tion or lower flight altitude was also identified in a drone-based study by Johansen et al. (2018) for lychee trees and by Zarco-Tejada et al. (2014) for olive trees. Contrary to this, the simulated results in Section 3.2.3 indicated that when the pixel GSD is identical at any given flight altitude, flying higher results in more accurate tree height estimation, although it also causes lower accuracy of PPC estimation at the same time. Therefore, to determine the optimal flight altitude for horticultural applications, the desired pixel GSD need to be carefully set based on the requirement of specific application of the multi-spectral imagery (Roth et al., 2018).

The forward overlap of photos within a flight line is often set to exceed $75 \%$ for most drone based studies of horticultural trees without any specific consideration of the consequences of increasing or decreasing the forward overlap (Singh and Frazier, 2018). Based on the analysis result of model 2 (Table 4), the forward overlap was considered as the most important variable for the data quality in terms of photo alignment, point cloud densification, and the estimations of tree height and PPC. Although higher forward overlap increased the tie point RMSE, it did not influence the accuracy of tree height estimation, possibly due to the built-in noise filtering function in the pre-processing software package. This finding matches the conclusion by Dandois et al. (2015) that the forward overlap has the most significant influence on the location accuracy and quality of the photogrammetric point cloud. Frey et al. (2018) suggested that forward overlap is even more important than the GSD regarding the 3D reconstruction of trees. However, they considered GSD as the only function of flight altitude regardless of the other side effects (i.e., average image area) that we evaluated in this study. From Table 4, we can tell that forward overlap was indeed the most dominant variable for normalised cloud density, but its dominance is similar to GSD with regards to tree height estimation. The threshold of forward overlap suggested by Dandois et al. (2015) was $80 \%$. Our results showed that both the point cloud density and the accuracy of the tree height estimation dropped significantly once the forward overlap fell below $80 \%$ (see Section 3.2.1). Limited consideration is often given to the setting of image side-lap, which tend to range from 60 to $80 \%$ in most studies (Colomina and Molina, 2014; Dandois et al., 2015; Patrick and Li, 2017; Singh and Frazier, 2018). Our analysis of horticultural trees suggested that a range between $70 \%$ and $80 \%$ is optimal to achieve the balance between the point cloud density and PPC estimation. As we discussed in Section 3.1.2, 

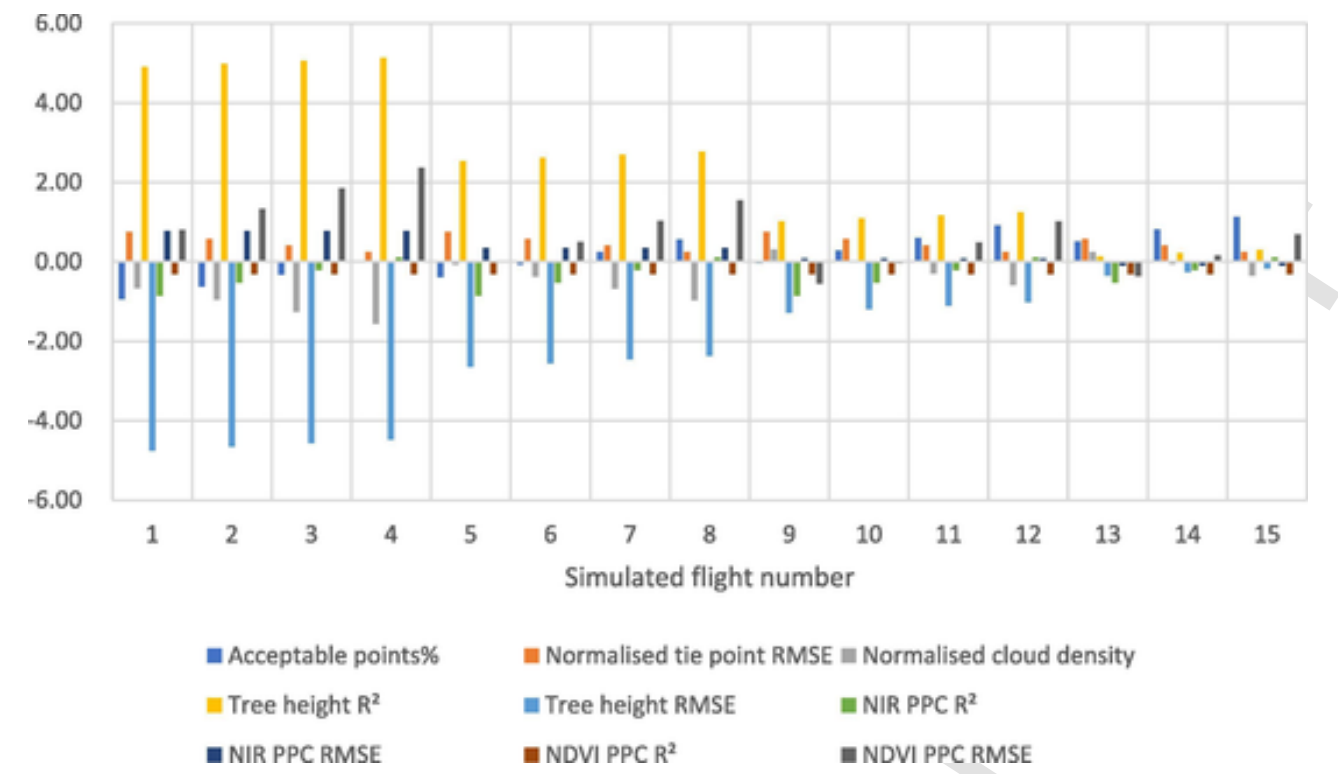

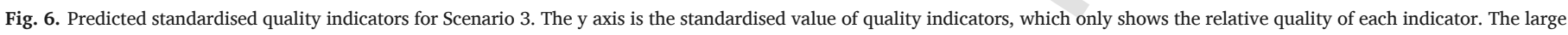
positive values of non-RMSE indicators represent better data quality, while the large negative values of RMSE indicators represent better data quality.

higher image side-lap increased the point cloud density but decreased the $\mathrm{R}^{2}$ of PPC estimation using NIR-based method. A similar result was also found in the study by Seifert et al. (2019), which suggested that higher side-lap increases the reconstruction details of trees but decreases the accuracy at the same time. The influence of speed on the accuracy of tree height estimation was uncertain in our experiment (see Section 3.1.4). This may be due to wind influencing the flying speed during individual flights. The wind speed during our experiment varied between 0 and $8 \mathrm{~m} / \mathrm{s}$ on the ground from east-southeast, causing uncertainty when analysing its impact. However, the trigger speed of most cameras are limited to a set number of frames per time interval due to the $\mathrm{I} / \mathrm{O}$ limit (Aasen et al., 2018; Roth et al., 2018). Therefore, this limit needs to be considered when planning the drone flight to satisfy the forward overlap requirement. The pitch angle caused by the flying speed can be resolved by tilted camera installation if no self-levelling gimbal is available. Several studies have indicated that a viewing angle exceeding 20 degrees significantly increases estimation error of tree height and other biophysical tree parameters (Cunliffe et al., 2016; Dandois et al., 2015). The average speed-induced pitch angle, which was estimated to be 2-17 degrees, still decreased the data quality. On the other hand, James and Robson (2014) demonstrated that the higher pitch angle improves the radial distortion of a derived DTM from self-calibrating bundle adjustment at the edge of survey area. The systematic radial distortion did not seem to affect the tree height estimation though, as the distortion is applied to both the DSM and DTM and is hence minimised when producing the CHM.

Research has shown that complex interactions exist between remotely sensed measurements of tree structural variables and illumination conditions (Tu et al., 2018; Wulder, 1998). Our results showed PPC estimation using the NIR-based method was the preferred option based on the analysis results in Section 3.2, as that enabled accurate estimation of both tree height and PPC at the same time. Although that acquiring remote sensing imagery around solar noon is almost a rule of thumb to guarantee higher data quality (Bauer et al., 1986; Zarco-Tejada et al., 2012), the idea of solar noon is ambiguous because the solar elevation during solar noon varies according to regions and seasons. Dandois et al. (2015) suggested that higher solar elevation results in better accuracy on tree structure measurement in a forest environment, yet similar studies on horticultural tree crops are absent, and the effect of solar elevation may possibly differ between natural for- est and artificially managed tree crops. The estimation accuracy of PPC using NIR information was particularly influenced by solar elevation (Table 4). In fact, higher solar elevation produced higher data quality assessed based on tie point RMSE, point cloud density, and the estimation of PPC. This corresponds to previous studies, also suggesting that the higher solar elevation provides a more accurate SfM point cloud for images captured either under clear sky or cloudy conditions (Dandois et al., 2015). However, the result in Table 4 shows that higher solar elevation slightly reduced the accuracy of tree height estimation. This may be because of the structural characteristics of avocado trees. The canopy structure of avocado trees is formed by several thrusting layers of branches and leaves that derivate from the main stem (Schaffer et al., 2013). This complexity of the tree canopy may cause features to be unidentified by the SfM algorithm due to lack of shadows creating within canopy contrast. This phenomenon may occur occasionally, and it is recommended that further research be undertaken on different types of tree crops or even avocado trees at different phenological stages to further assess interactions between tree canopy structure and solar elevation.

\section{Conclusions}

This study identifies a number of optimal drone flight variables that should be adopted when measuring tree height and PPC of horticultural tree crops. These include: (1) flying along the hedgerow, (2) using a smaller image pitch angle, (3) ensuring a high solar elevation, and (4) having an image side-lap of about $75 \%$. Image forward overlap is one of the most important variables that influence almost every quality indicator and should be set as high as possible $(>80 \%)$. When setting other variables such as flight altitude and flying speed, it must be ensured that there is sufficient image forward overlap to produce high quality data. The optimal altitude should be determined based on the required pixel GSD, which was demonstrated in the simulated optimal flight plans. Also, it was found that a higher flight altitude can sometimes produce more accurate measurements.

From these outcomes, it is suggested that future research should test whether results similar to our findings can be achieved with other camera systems, as this study only used the Parrot Sequoia ${ }^{\circledR}$ multi-spectral camera. Furthermore, future studies should focus on assessing the impacts on image radiometric quality instead of the indirect regressed PPC estimation, as the PPC is calculated based on the spectral and tex- 
tural information of tree crowns. Finally, it would be useful to evaluate whether outcomes can be extrapolated to other horticulture tree crops such as mango, macadamia, lychee, olive and citrus trees.

\section{Funding}

This research was funded by Department of Agriculture and Water Resources, Australian Government and Horticulture Innovation Australia as part of its Rural R\&D for Profit Program's subproject "Multi-Scale Monitoring Tools for Managing Australia Tree Crops - Industry Meets Innovation" [grant number RnD4Profit-14-01-008].

\section{Declaration of Competing Interest}

The authors declare that they have no known competing financial interests or personal relationships that could have appeared to influence the work reported in this paper.

\section{Appendix A. Supplementary material}

Supplementary data to this article can be found online at https://doi. org/10.1016/j.isprsjprs.2019.12.006.

\section{References}

Aasen, H., Honkavaara, E., Lucieer, A., Zarco-Tejada, J.P., 2018. Quantitative remote sensing at ultra-high resolution with UAV spectroscopy: a review of sensor technology, measurement procedures, and data correction workflows. Remote Sens. 10. doi: $10.3390 / \mathrm{rs} 10071091$.

Adeline, K.R.M., Chen, M., Briottet, X., Pang, S.K., Paparoditis, N., 2013. Shadow detection in very high spatial resolution aerial images: a comparative study. ISPRS J. Photogramm. Remote Sens. 80, 21-38. doi:10.1016/j.isprsjprs.2013.02.003.

Agisoft LLC, 2019. Agisoft Metashape User Manual: Professional Edition, Version 1.5. $<$ https://www.agisoft.com/pdf/metashape-pro_1_5_en.pdf > (accessed January 2019)

Asner, G.P., Warner, A.S., 2003. Canopy shadow in IKONOS satellite observations of tropical forests and savannas. Remote Sens. Environ. 87. doi:10.1016/j.rse.2003.08.006.

Barlow, C., 1997. Growth, structural change and plantation tree crops: the case of rubber. World Dev. 25, 1589-1607. doi:10.1016/S0305-750X(97)00059-4.

Bauer, M.E., Daughtry, C.S.T., Biehl, L.L., Kanemasu, E.T., Hall, F.G., 1986. Field spectroscopy of agricultural crops. IEEE Trans. Geosci. Remote Sens., vol. GE-24, pp. 65-75. DOI:10.1109/TGRS.1986.289589.

Bureau of Meteorology, Commonwealth of Australia Climate Data Onlineaccessed 19 Mar, 2019http://www.bom.gov.au/climate/data/index.shtml?bookmark = 2002019

Candiago, S., Remondino, F., De Giglio, M., Dubbini, M., Gattelli, M., 2015. Evaluating multispectral images and vegetation indices for precision farming applications from UAV images. Remote Sens. 7. doi:10.3390/rs70404026.

Cohen, P., West, S.G., Aiken, L.S., 2014. Applied Multiple Regression/Correlation Analysis for the Behavioral Sciences. Psychology Press.

Colomina, I., Molina, P., 2014. Unmanned aerial systems for photogrammetry and remote sensing: a review. ISPRS J. Photogramm. Remote Sens. 92, 79-97. doi:10.1016/ j.isprsjprs.2014.02.013.

Cunliffe, A.M., Brazier, R.E., Anderson, K., 2016. Ultra-fine grain landscape-scale quantification of dryland vegetation structure with drone-acquired structure-from-motion photogrammetry. Remote Sens. Environ. 183, 129-143. doi:10.1016/ j.rse.2016.05.019.

Dandois, J.P., Olano, M., Ellis, E.C., 2015. Optimal altitude, overlap, and weather conditions for computer vision UAV estimates of forest structure. Remote Sens. 7, 13895-13920. doi:10.3390/rs71013895.

Davies, F.T., Bowman, J.E., 2016. Horticulture, food security, and the challenge of feeding the world, 1128 ed. International Society for Horticultural Science (ISHS), Leuven, Belgium, pp. 1-6. DOI:10.17660/ActaHortic.2016.1128.1.

Deng, L., Mao, Z., Li, X., Hu, Z., Duan, F., Yan, Y., 2018. UAV-based multispectral remote sensing for precision agriculture: a comparison between different cameras. ISPRS J. Photogramm. Remote Sens. 146, 124-136. doi:10.1016/j.isprsjprs.2018.09.008.

Díaz-Varela, A.R., de la Rosa, R., León, L., Zarco-Tejada, J.P., 2015. High-resolution airborne UAV imagery to assess olive tree crown parameters using 3D photo reconstruction: application in breeding trials. Remote Sens. 7. doi:10.3390/rs70404213.

Econtech, Horticulture Australia, Australian Farm Institute, 2005. Australia's farm-dependent economy : analysis of the role of agriculture in the Australian economy. Australian Farm Institute, Surry Hills, N.S.W., Australia.

Eisenbeiß, H., 2009. UAV Photogrammetry, Dipl.-Ing., University of Technology Dresden. ETH Zurich, Zurich, Switzerland, p. 203.

Frey, J., Kovach, K., Stemmler, S., Koch, B., 2018. UAV Photogrammetry of Forests as a Vulnerable Process. A Sensitivity Analysis for a Structure from Motion RGB-Image Pipeline. Remote Sensing 10. DOI:10.3390/rs10060912.
Honkavaara, E., Khoramshahi, E., 2018. Radiometric correction of close-range spectral image blocks captured using an unmanned aerial vehicle with a radiometric block adjustment. Remote Sens. 10. doi:10.3390/rs10020256.

James, M.R., Robson, S., 2014. Mitigating systematic error in topographic models derived from UAV and ground-based image networks. Earth Surf. Proc. Land. 39, 1413-1420. doi:10.1002/esp.3609.

Jensen, J.R., 2016. Introductory Digital Image Processing: A Remote Sensing Perspective. fourth ed. Pearson Education Inc., Glenview, IL.

Jiménez-Brenes, F.M., López-Granados, F., de Castro, A.I., Torres-Sánchez, J., Serrano, N., Peña, J.M., 2017. Quantifying pruning impacts on olive tree architecture and annual canopy growth by using UAV-based 3D modelling. Plant Methods 13, 55 doi:10.1186/s13007-017-0205-3.

Johansen, K., Clark, A., Phinn, S., Witte, C., 2008. Mapping plant projective cover in riparian zones: integration of field and high spatial resolution QuickBird and LiDAR data. In: 14th Australasian Remote Sensing and Photogrammetry Conference, Darwin, Australia.

Johansen, K., Raharjo, T., McCabe, M., 2018. Using multi-spectral UAV imagery to extract tree crop structural properties and assess pruning effects. Remote Sens. 10, 854 doi: $10.3390 / \mathrm{rs} 10060854$.

Martens, H., Izquierdo, L., Thomassen, M., Martens, M., 1986. Partial least-squares regression on design variables as an alternative to analysis of variance. Anal. Chim. Acta 191, 133-148. doi:10.1016/S0003-2670(00)86303-5.

Nevalainen, O., Honkavaara, E., Tuominen, S., Viljanen, N., Hakala, T., Yu, X., Hyyppä, J., Saari, H., Pölönen, I., Imai, N.N., Tommaselli, M.G.A., 2017. Individual tree detection and classification with UAV-based photogrammetric point clouds and hyperspectral imaging. Remote Sens. 9. doi:10.3390/rs9030185.

Newett, S., McCarthy, A., Dirou, J., Miller, J., Hofman, P., Ireland, G., Pegg, K., Kernot, I., Searle, C., Ledger, S., Waite, G., Vock, N., 2001. Avocado Information Kit. Agrilink, your growing guide to better farming guide. In: Industries, D.o.P. (Ed.). Queensland Horticulture Institute, Brisbane, Queensland.

Novaković, P., Hornak, M., Zachar, M., 2017. 3D digital recording of archaeological. Architect. Artistic Herit. doi:10.4312/9789612378981.

Patrick, A., Li, C., 2017. High throughput phenotyping of blueberry bush morphological traits using unmanned aerial systems. Remote Sens. 9. doi:10.3390/rs9121250.

Pádua, L., Vanko, J., Hruška, J., Adão, T., Sousa, J.J., Peres, E., Morais, R., 2017. UAS, sensors, and data processing in agroforestry: a review towards practical applications. Int. J. Remote Sens. 38, 2349-2391. doi:10.1080/01431161.2017.1297548.

Rahman, M., Robson, A., Bristow, M., 2018. Exploring the potential of high resolution WorldView-3 Imagery for estimating yield of mango. Remote Sens. 10. doi:10.3390/ rs10121866.

Remondino, F., Spera, M.G., Nocerino, E., Menna, F., Nex, F., 2014. State of the art in high density image matching. Photogram. Rec. 29, 144-166. doi:10.1111/phor.12063.

Robson, A., Rahman, M.M., Muir, J., 2017. Using worldview satellite imagery to map yield in Avocado (Persea americana): A Case Study in Bundaberg, Australia. Remote Sens. 9. doi:10.3390/rs9121223.

Roth, L., Hund, A., Aasen, H., 2018. PhenoFly Planning Tool: flight planning for high-resolution optical remote sensing with unmanned areal systems. Plant Methods 14, 116. doi:10.1186/s13007-018-0376-6.

Saari, H., Pellikka, I., Pesonen, L., Tuominen, S., Heikkilä, J., Holmlund, C., Mäkynen, J., Ojala, K., Antila, T., 2011. Unmanned Aerial Vehicle (UAV) operated spectral camera system for forest and agriculture applications. In: Neale, C.M.U., Maltese, A., Richter, K. (Eds.), Remote Sensing for Agriculture, Ecosystems, and Hydrology XIII. SPIE, Prague, Czech Republic, pp. 81740H-81740H-81715. DOI:10.1117/12.897585.

Salazar-García, S., Garner, L.C., Lovatt, C.J., 2013. Reproductive biology. In: Schaffer, B., Wolstenholme, B.N., Whiley, A.W. (Eds.), The Avocado: Botany, Production and Uses, second ed. CAB International, Wallingford, Oxfordshire, UK, pp. 118-167.

Salgadoe, S.A., Robson, J.A., Lamb, W.D., Dann, K.E., Searle, C., 2018. Quantifying the severity of phytophthora root rot disease in avocado trees using image analysis. Remote Sens. 10. doi:10.3390/rs10020226.

Sarron, J., Malézieux, É., Sané, A.C., Faye, É., 2018. Mango Yield mapping at the orchard scale based on tree structure and land cover assessed by UAV. Remote Sens. 10. doi:10.3390/rs10121900.

Schaffer, B., Gil, P.M., Mickelbart, M.V., Whiley, A.W., 2013. Ecophysiology. In: Schaffer, B., Wolstenholme, B.N., Whiley, A.W. (Eds.), The Avocado: Botany, Production and Uses, second ed. CAB International, Wallingford, Oxfordshire, UK, pp. 168-199.

Seifert, E., Seifert, S., Vogt, H., Drew, D., van Aardt, J., Kunneke, A., Seifert, T., 2019. Influence of drone altitude, image overlap, and optical sensor resolution on multi-view reconstruction of forest images. Remote Sens. 11. doi:10.3390/rs11101252.

Sellers, P.J., 1987. Canopy reflectance, photosynthesis, and transpiration, II. The role of biophysics in the linearity of their interdependence. Remote Sens. Environ. 21, 143-183. doi:10.1016/0034-4257(87)90051-4.

Singh, K.K., Frazier, A.E., 2018. A meta-analysis and review of unmanned aircraft system (UAS) imagery for terrestrial applications. Int. J. Remote Sens. doi:10.1080/ 01431161.2017 .1420941$.

Torres-Sánchez, J., López-Granados, F., Borra-Serrano, I., Peña, J.M., 2018. Assessing UAV-collected image overlap influence on computation time and digital surface model accuracy in olive orchards. Precis. Agric. 19, 115-133. doi:10.1007/ s11119-017-9502-0.

Torres-Sánchez, J., López-Granados, F., Serrano, N., Arquero, O., Peña, J.M., 2015. High-Throughput 3-D Monitoring of agricultural-tree plantations with unmanned aerial vehicle (UAV) Technology. PLoS ONE 10, e0130479. doi:10.1371/ journal.pone.0130479.

Tran, T.N., Afanador, N.L., Buydens, L.M.C., Blanchet, L., 2014. Interpretation of variable importance in Partial Least Squares with Significance Multivariate Correlation (sMC). Chemometr. Intell. Lab. Sys. 138, 153-160. doi:10.1016/j.chemolab.2014.08.005. 
Tu, Y.-H., Johansen, K., Phinn, S., Robson, A., 2019. Measuring canopy structure and condition using multi-spectral UAS imagery in a horticultural environment. Remote Sens. 11. doi: $10.3390 / \mathrm{rs} 11030269$.

Tu, Y.-H., Phinn, S., Johansen, K., Robson, A., 2018. Assessing radiometric correction approaches for multi-spectral UAS imagery for horticultural applications. Remote Sens. 10, 1684. doi:10.3390/rs10111684.

Ushaa, K., Singh, B., 2013. Potential applications of remote sensing in horticulture-a review. Sci. Hortic. 153, 71-83. doi:10.1016/j.scienta.2013.01.008.

Viau, A., Jang, J.-D., Payan, V., Devost, A., 2005. The Use of Airborne LIDAR and Multispectral Sensors for Orchard Trees Inventory and Characterization.

Wang, C., Myint, S.W., 2015. A simplified empirical line method of radiometric calibration for small unmanned aircraft systems-based remote sensing. IEEE J. Select. Top. Appl. Earth Observ. Remote Sens., vol. 8, pp. 1876-1885. DOI:10.1109/JSTARS.2015.2422716.

Whiley, A.W., 2000. Avocado Production in Australia. in: Papademetriou, M.K. (Ed.), Avocado Production in Asia and the Pacific. Food and Agriculture Organization of the United Nations, Regional Office for Asia and the Pacific, Bangkok, Thailand, pp. 5-14.
Wold, S., Ruhe, A., Wold, H., Dunn, I.W., 1984. The Collinearity Problem in Linear Regression. The Partial Least Squares (PLS) Approach to Generalized Inverses. SIAM J. Scient. Stat. Comput. 5, 735-743. doi:10.1137/0905052.

Wu, D., Johansen, K., Phinn, S., Robson, A., Tu, Y.-H., 2019. Inter-comparison of Remote Sensing Platforms for Height Estimation of Mango and Avocado Tree Crowns (submitted to Journal of Applied Earth Observation and Geoinformation for review)

Wulder, M., 1998. Optical remote-sensing techniques for the assessment of forest inventory and biophysical parameters. Prog. Phys. Geogr.: Earth Environ. 22, 449-476. doi:10.1177/030913339802200402.

Zarco-Tejada, P.J., Diaz-Varela, R., Angileri, V., Loudjani, P., 2014. Tree height quantification using very high resolution imagery acquired from an unmanned aerial vehicle (UAV) and automatic 3D photo-reconstruction methods. Eur. J. Agron. 55, 89-99. doi:10.1016/j.eja.2014.01.004.

Zarco-Tejada, P.J., González-Dugo, V., Berni, J.A.J., 2012. Fluorescence, temperature and narrow-band indices acquired from a UAV platform for water stress detection using a micro-hyperspectral imager and a thermal camera. Remote Sens. Environ. 117. doi:10.1016/j.rse.2011.10.007. 